\title{
Earnings inequality and the changing nature of work
}

Evidence from Labour Force Survey data of Bangladesh

Sayema Haque Bidisha, ${ }^{1}$ Tanveer Mahmood, ${ }^{2}$ and Mahir A. Rahman $^{2}$

January 2021 
Abstract: With structural changes in production coupled with technological progress, there have been shifts in modes of production and patterns of employment, with important consequences on task composition of occupations. This paper has utilized different rounds of Labour Force Survey data of Bangladesh and combined it with occupation network data of the United States along with its country-specific database and analysed the role of such factors on labour market outcomes. Our analysis shows a fall in the average routine intensity of tasks with no evidence of job polarization. We find a decline in earnings inequality where the decomposition analysis shows that earnings structure effect rather than characteristics effect plays a key role, with routine-task intensity of jobs and education explaining the majority of differences in earnings. Our analysis suggests that investing in education should be the highest priority, with greater emphasis on skillbiased training programmes, particularly those involving cognitive skill.

Key words: Labour Force Survey, inequality, job polarization, education premium, routine-task intensity, decomposition, Bangladesh

JEL classification: D31, O53, J21, J24

Acknowledgements: This paper is an output of a cross-country research project of the United Nations University World Institute for Development Economics Research (UNU-WIDER), Helsinki. The paper's findings were presented at the 2020 Online Jobs and Development Conference, organized by the World Bank, the Institute of Labor Economics, and UNU-WIDER. The authors are thankful to the participants of the conference for their useful comments. Usual disclaimer applies.

Note: The online Methodological and Technical Appendices are available here.

\footnotetext{
${ }^{1}$ Department of Economics, University of Dhaka, Bangladesh, corresponding author: sayemabidisha@gmail.com; 2 Bangladesh Institute of Development Studies (BIDS), Dhaka, Bangladesh

This study has been prepared within the UNU-WIDER project The changing nature of work and inequality.

Copyright (C) UNU-WIDER 2021

UNU-WIDER employs a fair use policy for reasonable reproduction of UNU-WIDER copyrighted content—such as the reproduction of a table or a figure, and/or text not exceeding 400 words - with due acknowledgement of the original source, without requiring explicit permission from the copyright holder.

Information and requests: publications@wider.unu.edu

ISSN 1798-7237 ISBN 978-92-9256-941-9

https://doi.org/10.35188/UNU-WIDER/2021/941-9

Typescript prepared by Ayesha Chari.

United Nations University World Institute for Development Economics Research provides economic analysis and policy advice with the aim of promoting sustainable and equitable development. The Institute began operations in 1985 in Helsinki, Finland, as the first research and training centre of the United Nations University. Today it is a unique blend of think tank, research institute, and UN agency-providing a range of services from policy advice to governments as well as freely available original research.
}

The Institute is funded through income from an endowment fund with additional contributions to its work programme from Finland, Sweden, and the United Kingdom as well as earmarked contributions for specific projects from a variety of donors.

Katajanokanlaituri 6 B, 00160 Helsinki, Finland

The views expressed in this paper are those of the author(s), and do not necessarily reflect the views of the Institute or the United Nations University, nor the programme/project donors. 
There is a growing body of literature on the issue of structural changes in production coupled with technological progress, which has led to a significant shift in modes of production as well as in patterns of employment. Such a changed pattern of production is expected to have consequences on employment, with even destruction of certain types of jobs. With changed employment status (and maybe even with unemployment), earnings of individual workers with differing skill levels are expected to change as well, resulting in changes in income distribution across different skill groups. This skill-biased technological change and shift in production process are expected to raise income inequality (Berman and Machin 2000). A recent study in this context argues that, based on the task content of work, ${ }^{1}$ the effect of structural transformation on earnings inequality differs (Acemoglu and Restrepo 2017). Besides, with globalized market and increased international trade, certain types of production and related tasks are being shifted from developed to developing countries. As Autor et al. (2015) argue, the effect of trade and technology on the labour market and earnings should be understood together. Based on such argument, over time, as a result of several factors such as structural transformation, international trade, technology-induced change in the production process, and changing demand, the task content of jobs is expected to change. This change is likely to differ across countries, based on their pattern of structural change as well as the skill content of jobs.

The pattern of change of task content is expected to differ between the developed and developing countries in particular. The skill level of the workers along with their socio-demographic features can have important implications as well. All such factors can have implications on inequality in income; thus, it is important to understand the factors related to the labour market that might have implications for income inequality as a whole. In the context of developing countries like Bangladesh, the nexus between labour market variables and income inequality can be more complex due to an imperfect labour market, absence of trade union, large agriculture sector in the economy, flow of remittances, transfer to the poor, etc. As Osmani and Sen (2011) pointed out, it was primarily transfer income that was responsible for inequality in rural areas in Bangladesh during the 2000s. There is also the argument that, on the one hand, the lower growth of real wages compared with the growth in labour productivity has helped the country to accelerate the growth process, while on the other hand, it has raised the share of non-labour factors of production but lowered the share of labour factors of production, thereby shifting the distribution of income against labour (Osmani 2015a, b). In case of the contribution of different components of income on inequality, wages in rural areas have been found to have an equalizing effect on the distribution whereas wages and entrepreneurial income from farming in urban areas have an equalizing effect on distribution (Khan and Sen 2001).

Against this backdrop, the present paper attempts to understand the effect of the changing nature of jobs on the labour market of Bangladesh. In particular, this study aims to explore the changes in the task content of jobs over time and the resulting impact of such changes on the earnings distribution of workers with differing skill levels. It aims at analysing the role of routine-biased technological change and skill-biased technological change on earnings distribution by applying several descriptive and econometric tools. The analysis uses different rounds of Labour Force Survey (LFS) data of Bangladesh and combines it with US Occupational Information Network

\footnotetext{
${ }^{1}$ Here, task content indicates the degree of cognitive skill embodied in work, routine nature of a job, etc.
} 
$(\mathrm{O} * \mathrm{NET})$ data as well as country-specific O*NET dataset for tracing the returns to different tasks over time.

Our analysis has a number of important implications. First, tracing the changes in key labour market statistics of Bangladesh over a period of around 12 years, we find that there has been an overall increase in educated workforce leading to a corresponding increase in high-skilled workers. Second, in terms of real earnings, almost all education groups have experienced an increase and those with tertiary education have experienced a sharp rise in education premium. Third, in the context of Bangladesh, the analysis does not provide evidence in favour of polarization in employment; rather, our estimation confirms earnings polarization. Fourth, for the first time in the context of Bangladesh, utilizing unique country-specific datasets of task content measures, this study has analysed the trend in skill-biased task content embodied in occupations and also explored the link between changes in skill content and inequality in earnings. Our results show that over the entire time period there has been a fall in average routine-task intensity (RTI), with a moderate decline in earnings inequality over time. Fifth, utilizing a number of decomposition measures the paper reveals that inequality can be mostly explained by within-occupation differences where the dominance of between-occupation differences have grown over time. Also, primarily earnings structure effect rather than characteristics effect is found to play a key role behind changes in inequality over time, with RTI of jobs and education explaining the majority of differences in earnings for different earnings quantiles.

In the face of ongoing structural transformation and automation on the one hand and low skill content and unemployment on the other, this analysis is expected to provide important policy insights for the labour market strategies of Bangladesh. Based on our findings, we suggest that given high education premium, investing in education should be the highest priority. With the declining importance of routine-intensive tasks, greater emphasis is needed towards skill-biased training programmes, particularly those involving cognitive skill. With structural shift towards less routine-intensive tasks and better skilled workforce, it would be pertinent to bring more sectors under the coverage of minimum wage law and to establish trade unions to ensure that benefits emanating from such a structural change is distributed evenly across all worker groups. In addition, the falling trend of earnings inequality as revealed by our findings should be interpreted with caution as a number of factors, including low revenue generation capacity of the economy, institutional weaknesses, etc., must be considered to analyse inequality.

The paper is organized as follows: Section 2 offers a snapshot of the overall economic profile of Bangladesh. Section 3 provides a brief overview of relevant literature. Section 4 outlines the sources of data and methodological issues of the paper. Section 5 discusses the empirical findings of the research. Finally, Section 6 summarizes and concludes.

\section{A brief overview of economic profile of Bangladesh}

Bangladesh is a densely populated South Asian country that has achieved the status of a lowermiddle-income country in 2015 and is aspiring to reach the least-developed country status by 2024 . Over the past decade or so, the country has been able to attain an annual growth rate of more than 6 per cent on average, accompanied by impressive progress in several socio-economic indicators, such as fertility, child mortality, and gender parity in primary education (Raihan and Bidisha 2018) (Appendix Figure A1). In fiscal year 2019, the country registered a record growth of more than 8 per cent. Two of the major drivers of economic growth in Bangladesh are argued to be export earnings from the ready-made garments (RMG) industry and remittances sent by international migrants. Remittances from international migrants stood at 18.21 billion USD during 2019-20 and 
have been playing a key role in the reduction of poverty and improving the welfare of rural people in particular. On the other hand, the RMG sector accounts for more than 84 per cent of total export earnings of the country and currently Bangladesh is the second largest exporter after China. With 34 billion USD of export in the fiscal year of 2019 and around 4 million employees, more than half of which are women (around 65 per cent), it is aiming to accomplish a benchmark of 100 billion USD of export earnings by 2020 (Export Promotion Bureau 2020). Although primarily labour-intensive, the RMG industry is slowly adopting capital-intensive technologies and machinery, which is expected to have important implications towards employability in the sector (Raihan and Bidisha 2018).

Despite its success in accelerating GDP growth, one concern of Bangladesh is that of growing inequality. Although the Gini index of household income has come down from 0.467 to 0.458 from 2005 to 2010, the trend has started to reverse with the index being 0.483 in 2016 (Appendix Table A1). ${ }^{2}$ One important point to note here is that, although both rural and urban areas have registered rise in inequality, the latter has experienced a sharp rise in recent years (Osmani 2017, 2018). Also, although income inequality has risen almost consistently (except the fall during 200510), consumption inequality has remained almost stable, especially in recent years (2010-16). As argued by Osmani (2017), this difference between inequality in income and consumption can partially be attributable to a number of factors, including the relatively higher marginal propensity to consume than those in the lower end of the distribution. Expansion of microcredit programmes has arguably been an important factor in relaxing the binding in liquidity for lower-income rural households (Osmani 2017). Factors like transfer income and external remittances have also contributed significantly towards poverty reduction in rural areas. Transfer income has been found to be the most important factor in driving inequality in rural areas (Osmani and Sen 2011). Therefore, the interplay among changes in task component, structural transformation along with other economy-specific factors like microcredit operations, and transfer income along with remittances can have interesting implications on overall inequality.

In addition to the discrepancies in income and consumption inequality, it is often argued that the country has not been able to translate its growth in the labour market with low employment elasticity of growth rate in recent years (Appendix Table A2). The labour market is also highly informal, with more than 85 per cent of workers employed in the informal sector. This informality in employment is particularly crucial in terms of sustainability in earnings in the face of any economic shock or due to major shifts in the skill-biased production process. Also, with a female labour force participation rate of around 36 per cent as opposed to a male labour force participation rate of more than 80 per cent, there exists a high degree of gender disparity in the labour market where the representation of the former in high-skilled and high-paid jobs is quite low as well (Appendix Tables A3 and A4). Furthermore, a high degree of skill mismatch between demand and supply in the labour market has resulted in a high rate of unemployment among educated youths. With the ongoing demographic transition, youth unemployment and youth not in any employment, education, or training are obstructing the path towards reaping the benefits of demographic dividend. According to LFS data, 29.9 per cent of youth in the age group of 15-29 years are found to be not in any employment, education, or training activities, with the rate being as high as 49 per cent for female youth (BBS 2018).

Another crucial aspect of the labour market is that of low skill content of its workforce: this is argued to be of concern for the growing challenges of automation and industrialization (Raihan

\footnotetext{
2 We should keep in mind that this trend in Gini index is based on the Household Income and Expenditure Survey (2016-17) of Bangladesh (see BBS 2019), which may differ from the findings of other surveys like that of the Labour Force Survey used in our analysis.
} 
and Bidisha 2018). On the one hand, around 30 per cent of the labour force has no formal education; on the other hand, only around 7-8 per cent of the workforce has a tertiary level of education (BBS 2018; see Table 1). Higher percentages of workers have primary and secondary education and are concentrated in lower mid-skilled occupations. Therefore, it can be argued that the benefits of higher per capita income and high growth of GDP have not been distributed proportionately across different education and skill levels, leaving a majority of Bangladesh's workforce (especially those without tertiary education) with relatively lower returns to education.

In the context of its experiences of structural transformation, over time although the share of agriculture in the GDP of Bangladesh has come down to around 15 per cent, with a corresponding increase in the share of the industrial sector to 32 per cent, this structural shift has been quite disproportionate if we look at the labour market. For example, 40 per cent of the labour force, with an overwhelming percentage of women ( 60 per cent), are engaged in agriculture, whereas only around 20 per cent of those employed are found to be in the industrial sector (Appendix Table A5). Another important feature of the structure of production and employment in the country is a high share of the service sector in GDP: 53 per cent of GDP originates from this sector, with an employment share of around 39 per cent (Ministry of Finance 2019). The mode of structural transformation is driven by service rather than industry and that has been reflected in both production as well as in employment. The slow pace of structural transformation led by the service sector can have implications towards the distribution of earnings. Discussing the type of structural transformation in Bangladesh, Raihan and Khan (2020) emphasized very low level of complexity in the manufacturing sector and lack of diversification as key challenges for tackling inequality and attaining inclusive growth.

Being a labour-abundant and capital-scarce country, the production process as a whole is also strongly driven by a labour-intensive mode of production with relatively simple technology. However, for the last decade or so, in particular, there has been a moderate shift towards modern technology in the production process. With its fast growth momentum on the one hand and the challenges of the fourth industrial revolution on the other, it is expected that Bangladesh is increasingly moving towards a more capital-intensive mode of production. It is therefore important to understand whether and how changed occupational structure has contributed towards the distribution of earnings.

\section{Literature review}

Autor et al. (2003) studied the impact of adopting changing technology (as represented by computerization) on task composition and the subsequent changes in the type of labour demanded across and within industries. Using pair representative data on job task requirements from the Dictionary of Occupational Titles and with samples of employed workers from the Census and Current Population Survey, Autor et al. (2003) formed a consistent panel of industry and occupational task input over four decades (1960-98). Their paper found evidence that the introduction of computerization could substitute workers who performed routine cognitive and manual tasks and complement workers in non-routine problem solving and other complex tasks. Such shifts in labour input favouring non-routine over routine tasks were concentrated in rapidly computerized industries. According to their analysis, these shifts were small and insignificant in the pre-computer decade of the 1960s, and accelerated in each subsequent decade, indicating that these changes were indeed caused by the gradual and rapid adoption of computer-based technology. This can give rise to job polarization in an economy where introduction of new technology can cause a rise in relative demand of highly paid, skilled jobs (i.e. jobs requiring non-routine cognitive skills) and low-paid low-skilled jobs (i.e. jobs requiring non-routine manual skills) and, conversely, cause a fall in 
relative demand of mid-skilled jobs (i.e. jobs requiring routine manual and cognitive skills). This hypothesis was further explored by Goos and Manning (2007), who found evidence of job polarization in the United Kingdom. Furthermore, Sebastian (2018), using various waves of the Spanish LFS, explored the evolution of job polarization between 1994 and 2014. First, the study showed a U-shaped relationship between employment share growth and job percentile in the wage distribution. Second, it explored the task content of jobs using the European Working Condition Survey and showed that changes in employment shares were negatively related to computerization. Finally, using the information about past jobs, it provided evidence of displacement of mid-paid workers.

Acemoglu and Autor (2011) emphasized the importance of interaction among skill of workers, the content of tasks they perform, change in technology, and the shift in trading patterns in explaining the changes in earnings and employment patterns in developed countries like the United States. They utilized data of the US economy and their model is strongly based on the task content of work, where tasks are the basic production units. The authors assumed endogeneity in assigning skills to tasks and inferred that technological change may involve the substitution of machines for some specific tasks that would otherwise be performed by labour. In a similar line of analysis, Autor and Dorn (2009) have tried to explain the phenomenon of job polarization in greater detail and found a shift in the employment of mid-skilled workers who were involved in routine tasks. They supported their analysis with 25 years of data of the US labour market, where they found a reduction in routine employment and resulting shift towards low skill, non-routine work. Alongside the reduction of mid-skilled non-college workers in high-paying cities and diminishing urban wage premium for non-college workers, there has been a reduction in real wages for noncollege workers. The authors concluded that, in comparison to college-educated workers, technology-induced changes in the nature of work have not benefited non-college workers. In this connection, using Current Population Survey data, Firpo et al. (2011) argued that changes in the returns to occupational tasks have a significant impact on the changes in the wage distribution over the last decades and offshorability of tasks had an important role in this regard. As for developing countries, Osmani (2015a, b) pointed out that it is rather the lower growth in real wages than in productivity of labour that has resulted in acceleration in the growth of Bangladesh along with a distributional income shift away from labour. Osmani $(2015 \mathrm{a}, \mathrm{b})$ also emphasized the role of foreign remittance flow in case of both high growth and increasing inequality in Bangladesh.

Exploring the implication of automation and artificial intelligence (AI) on the demand for labour, wages, and employment, Acemoglu and Restrepo (2018) devised a framework that dealt with the dichotomy of displacement of labour involved in tasks where machines and AI have replaced labour in tasks and increased demand for labour in non-automated tasks due to an increase in productivity because of automation. Their study further argued that the counterbalancing effects of these two might result in a reduction in the share of labour in national income. So, they suggested that a more powerful counterbalancing force would be the creation of new labourintensive tasks.

In the context of regional experiences of structural transformation and RTI studies on India, Kuriakose and Iyer (2020) reflected that over-supply of the secondary- and tertiary-educated labour force has resulted in mid-skilled workers moving from mid-skilled jobs to relatively lowskilled manufacturing and service occupations in India, causing routine occupations to persist. This phenomenon has also led to job polarization and consequent wage polarization towards high- and low-skilled occupations at the expense of mid-skilled occupations. In the context of Bangladesh, to the best of our knowledge, no study has attempted to understand the polarization of employment and earnings. 
Analysing the evolution of the task content of jobs in India between 1983 and 2011, Vashisht and Dubey (2018) found that non-routine cognitive analytical, as well as non-routine cognitive interactive, task intensity of jobs has increased in India, while manual task intensity has declined. On the other hand, in contrast to the United States and Europe, the routine cognitive task content has not declined in India over time.

Using representative survey data (such as STEP, PIAAC, CULS, etc.) of 42 countries, Lewandowski et al. (2019) explored the phenomenon of the shift from manual and routine cognitive work to non-routine cognitive work. They devised a measure of task content of jobs that were consistent with the O*NET database-based occupation-specific measures. They estimated the determinants of workers' RTI as a function of technology (computer literacy), globalization, structural change, and supply of skills, and decomposed their role in accounting for the variation in RTI across countries. The study showed that computer skills and quality of education were negatively associated with the level of RTI. Additionally, globalization (measured by sectors' foreign value-added share) has caused an increase in RTI in poorer countries whereas the opposite scenario could be seen in richer countries. It also showed that technology and globalization tend to have different impacts on different groups of workers: change in technology has caused a change in RTI among workers in high-skilled work and for non-offshorable occupations, whereas globalization has caused a change in RTI among workers with low skill and for offshorable occupations. In addition, developing countries may experience certain different sets of factors that may have implications on inequality. For example, the Gini decomposition result of Osmani and Sen (2011) in the context of Bangladesh has reflected that transfer income has primarily been responsible for the rising trend in rural inequality during the 2000s. In particular, through a detailed decomposition analysis the researchers found foreign remittances accounted for as much as 70 per cent of the rise in rural inequality during the 2000s, with self-employment in non-agriculture being another important factor for the rising trend in rural Gini. Both salary as well as other income in non-agriculture sector had an equalizing effect during that time period. Khan and Sen (2011), while analysing inequality in Bangladesh, also asserted that due to the rising share of certain components of income which have a de-equalizing effect, there was increase in inequality during the early 1990s. In particular, they found rural wages have an equalizing effect on income distribution with the income from subsistence component of farming having an equalizing effect but other sources of rural income (e.g., transfer, property income, and miscellaneous income) have a dis-equalizing effect. As for urban income, the authors have found that wage and entrepreneurial farming income have an equalizing effect whereas wages from non-farm employment tend to have a dis-equalizing effect.

While exploring the role of evolution of the task content of jobs and how the nexus of technology and trade has transformed the nature of work in different countries, most of the existing studies have used US O*NET data to analyse task demand (Apella and Zunino 2018; Arias et al. 2014; Du and Park 2018; Hardy et al. 2018a, b; Lewandowski et al. 2020), leading to the assumption that the task content of each occupation is identical to that of the United States. Given large differences in labour productivity, technology adoption, and skills supply, this assumption is questionable especially when we consider the experience of developing countries (Eden and Gaggl 2020; Hsieh and Klenow 2010). It is expected that specific occupations utilize different skillsets and perform different tasks in low-, middle-, and high-income countries. In particular, poorer countries may specialize in routine tasks and richer countries may specialize in non-routine tasks (Grossman and Rossi-Hansberg 2008). Against this backdrop, using survey data of 46 low-, middle-, and highincome countries, Lewandowski et al. (2020) found that occupations in low- and middle-income countries are more routine-intensive than those in high-income countries, especially in high-skilled occupations (International Standard Classification of Occupations, ISCO 1-3). They argued that these international differences in the RTI of occupations are mainly caused by lower technology 
adoption in less-developed countries. Moreover, combining these findings with employment data of 87 countries that represent more than 2.5 billion workers ( 75 per cent of global employment), Lewandowski et al. (2020) found that, since the 2000s, the gross reallocation of labour away from routine work and non-routine work has occurred much more slowly in low- and middle-income countries than in high-income countries. As a consequence, the gap between these groups of countries in terms of average RTI has widened. High-income countries have remained the dominant supplier of non-routine work, whereas low- and middle-income countries have remained the dominant supplier of routine work. In contrast, using conventional O*NET task measures, which assume that occupations are identical around the world, Lewandowski et al. (2020) found that the average RTI has been declining in all country groups at a similar pace.

\section{$4 \quad$ Data and methodology}

\subsection{Sources of data}

In our analysis, we have utilized three rounds of cross-sectional LFS data: 2005/06 (hereafter 2005), 2010, and 2016/17. These three rounds contain the basic information of socio-demographic characteristics of individuals, level of education, status in the labour market, earnings from employment, as well as ISCO occupational classification at the four-digit level. Although the three separate datasets are not the same ISCO classification, we converted data of all three waves to ISCO-88 classification. Here, 2005 and 2010 data are cross-sectional data whereas 2016/17 data is quarterly data that has been converted to annual data using annual weights. ${ }^{3}$

In terms of our sample of individuals, we considered those within the age range of 15-64 years and confined the sample to only those who worked for at least 1 hour for pay or profit of households in the last 7 days before the survey. The occupational categorization was done based on primary work of the individual. As for earnings data, we included the weekly earnings of the workers and converted the earnings data from monthly to weekly in case of the last wave of LFS (i.e. QLFS 2016/17). ${ }^{4}$ We have considered weekly earnings of only the wage employed and, for the sake of comparability, we adjusted earnings data for inflation (wage changes has been considered with respect to 2010). ${ }^{5}$

For the variables in our analysis, in the case of education, four categories have been considered: (i) no education, (ii) primary education, (iii) secondary education, and (iv) tertiary education. For skill level, we have considered the one-digit ISCO classification, which includes (i) managers, (ii) professionals, (iii) technicians and associate professionals, (iv) clerical support workers, (v) services and sales workers, (vi) skilled agriculture/forestry/fishery, (vii) craft and related trade, (viii) plant and machine operators and assemblers, and (ix) elementary occupations. In this analysis, we also considered a simplified categorization of skills: (i) low skill (elementary occupation and skilled agriculture/forestry/fishery), (ii) medium skill (clerical support workers, services and sales workers, craft and related trade workers, plant and machine operators/assemblers), and (iii) high skill (managers, professionals, technicians, and associate professionals).

\footnotetext{
${ }^{3}$ We should keep in mind that although 2016/17 data is a rotating panel with one individual repeated twice, the standard errors could be higher.

4 To ensure consistency across datasets, for 2005 we have cleaned the dataset. For details please check the online Technical Appendix.

${ }^{5}$ We have used the consumer price index to adjust for inflation.
} 
In addition to country-wise LFS data, we have also used the O*NET database developed by the US Department of Labour/Employment and Training Administration, which contains standardized and occupation-specific information for almost thousands of occupations in the US economy. In particular, a specific segment of it ( $\mathrm{O}^{*} \mathrm{NET}$ content model) consisting of information on required task content (related to knowledge, skill, and abilities required to accomplish a certain task) has been utilized. The final database of the study was prepared by merging O*NET data with LFS data so that each worker's occupation, based on the four-digit ISCO classification, can further be decomposed into the associated tasks of those jobs. In this regard, following Autor et al. (2003), five categories of tasks have been considered: (i) routine cognitive, (ii) non-routine cognitive analytical, (iii) non-routine cognitive interpersonal, (iv) routine manual, and (v) non-routine manual. Therefore, the resulting data file has a disaggregated task-based occupational classification of each individual. Given that the LFS dataset contains information of earnings of individuals, combining these two it is possible to track the return to different types of tasks. With different cross-sections $(2005,2010$, and 2016/17) spanning a reasonably long time period, we have tried to understand how (and whether) the task composition of occupations have evolved and how returns to such skills have changed. However, this approach is based on a strong assumption that the task content of each occupation is the same across different countries. In this regard, due to the differences in productivity, adoption of technology, level of education, and skill of the workers, as argued by Lewandowski et al. (2019) and Lo Bello et al. (2019), there can be differences in skill sets utilized by different occupations in different countries. In particular, as discussed by Lewandowski et al. (2020), ${ }^{6}$ this difference is likely to be more pronounced among developed and developing countries. ${ }^{7}$

The measures of task content in connection with our survey data are consistent with those using O*NET. We considered the following four task content categories:

- Routine manual: these include tasks of (i) operating vehicles, mechanized devices, or equipment; (ii) spending time using hands to handle, control or feel objects, tools or controls; (iii) manual dexterity; and (iv)spatial orientation.

- Routine cognitive: these involve (i) the importance of repeating the same tasks; (ii) the importance of being exact or accurate; and (iii) structured versus unstructured work.

- Non-routine cognitive analytical: these include tasks that involve (i) analysing data/information; (ii) thinking creatively; and (iii) interpreting information for others.

- Non-routine cognitive interpersonal: these include tasks like (i) establishing and maintaining personal relationships; (ii) guiding, directing, and motivating subordinates; and (iii) coaching/developing others.

We followed the literature (Goos et al. 2014; Autor and Dorn 2009) and combined these four measures of tasks into a composite index of RTI and used the following formula:

$$
R T I=\ln \left(\frac{r_{\text {cognitive }}+r_{\text {manual }}}{2}\right)-\ln \left(\frac{n r_{\text {analytical }}+n r_{\text {personal }}}{2}\right)
$$

In this specification, unlike Autor and Dorn (2009) following Hardy et al. (2018a, b), Lewandowski (2017), Lewandowski et al. (2019), non-routine manual tasks have been dropped.

\footnotetext{
${ }^{6}$ See Section 3 for a discussion on the motivation of using country RTI as opposed to O*NET RTI.

${ }^{7}$ In this connection, as suggested by Hardy et al. (2018a, b), we have constructed country-specific task measures for Bangladesh.
} 


\subsection{Regression of changes in employment and earnings on the level of RTI}

To investigate the relationship between changes in employment and earnings and the changes in the task composition of occupations for sub-periods 2005-10 and 2010-16/17 and the entire period 2005-16/17, we applied several econometric methods. In this section, a brief rationale for using these methods are discussed. Detailed description of these methods can be found in the online Methodological Appendix.

Given that one of our key objectives is to understand the way employment and earnings have evolved across different skill levels, we re-classified occupation groups according to task-based skill contents, as discussed in Section 4.1. Following Sebastian (2018), we examined the effect of the evolution of RTI of occupations on changes in employment and earnings over time.

To get better insight into the relationship between changes in employment and earnings based on the skill level of workers, it is often interesting to check whether there has been any polarization of employment and earnings over time. As a simple test of polarization, following Goos and Manning (2007) and Sebastian (2018), we applied a regression-based test of job and earnings polarization.

To get better insight into the linkage between education and earnings and to understand the trend of education premium, we attempted to utilize a parametric method. Following three different versions of equations, we obtained education premium for different education groups. The simplest one only used education categories as the regressors. In the second version, we estimated the variant with education categories, age group, region, and religion as regressors. The final variant included all the regressors used in the second model and also two-digit ISCO-88 occupation categories.

To explore the role of occupations and tasks performed by workers in explaining the trends of income inequality, we can distinguish the 'between-group' effect-differences in earnings among workers performing different tasks (i.e. those who are employed in different occupations) from the 'within-group' effect—-differences in earnings among workers performing similar tasks (i.e. those who are employed in the same occupation but differ in other personal or job characteristics, such as skills, experience, geographic location, or formality status, etc.). The Shapley decomposition technique considers the marginal effect of eliminating each of the contributory factors in a sequence and assigns each factor the average of its marginal contributions in all possible elimination sequences. This procedure yields an exact additive decomposition of the chosen inequality index into the desired number of contributions and this is formally referred to as the Shapley value. Following Chantreuil and Trannoy (1997) and Shorrocks (2013), we have decomposed earnings inequality (measured most commonly by the Gini index) into two key components: (i) changes in 'within-occupation inequality' and (ii) changes in 'between-occupation inequality' (as measured by two-digit ISCO-88 codes).

The recentred influence function (RIF) regression-based decomposition method introduced by Firpo et al. $(2009,2011)$ tries to explain the wage gap between two groups by decomposing it into two effects: 'composition effect' (the part related to the differences in the observed characteristics of these groups) and 'earning structure effect' (the part related to the differences in the returns to the characteristics of these groups). In contrast to the conventional decomposition analysis, these two groups can also be considered as two different time periods. 
Given that the primary purpose of this research is to understand the linkage between employment and earnings inequality, we attempted to utilize a variety of graphs and tables to get better insights into the relationship. Also, several estimations and decomposition techniques have been utilized to understand the research objectives of the study. In Section 5.1, we first examine the distribution of workers in terms of basic education and occupational categories as well as pattern and trend of skill-biased occupational classification. Next, we apply several regression-based techniques to better understand changes in the task composition of occupations over time and to test polarization of employment and earnings over time as discussed in Sections 5.2 and 5.3, respectively. In Section 5.4, we link employment and education with earnings and attempt to understand the pattern of education premium. In Section 5.5, we attempt to explain earnings inequality over time using several methods used in literature. Finally, in Section 5.6, decomposition analysis of inequality is used to analyse the factors behind changes in inequality over time.

\subsection{Distribution of workers by education and skill levels}

As shown in Table 1, education-based labour market profile of workers reflects a low representation of both men and women in tertiary education (7 per cent in 2016/17) where the latter's position is even worse: only 5.74 per cent of women were in tertiary education in 2016/17. On the other hand, although the situation has improved over time, there is an overwhelming proportion of the labour force without any schooling: in 2016/17, the percentage was almost onethird of the total employed population (29.98 per cent). Another quarter of workers were found to have primary education only (around 26.43 per cent) (Table 1). Over time, however, although there has been a large decline (10.42 per cent during the entire period) of those without any formal education, there is a steady increase of those with secondary education (6.24 per cent increase).

Table 1: Distribution of workers by gender and level of education (\%)

\begin{tabular}{|c|c|c|c|c|c|c|c|c|c|}
\hline \multirow{2}{*}{$\begin{array}{l}\text { Highest level of education } \\
\text { completed }\end{array}$} & \multicolumn{3}{|c|}{ Male } & \multicolumn{3}{|c|}{ Female } & \multicolumn{3}{|c|}{ Total } \\
\hline & 2005 & 2010 & $2016 / 17$ & 2005 & 2010 & $2016 / 17$ & 2005 & 2010 & $2016 / 17$ \\
\hline No schooling & 36.98 & 39.75 & 28.22 & 51.64 & 40.79 & 35.68 & 40.4 & 40.07 & 29.98 \\
\hline Primary & 24.5 & 23.29 & 27.35 & 23.35 & 23.07 & 23.44 & 24.23 & 23.22 & 26.43 \\
\hline Secondary & 32.94 & 32.2 & 37.05 & 21.89 & 33.98 & 35.14 & 30.36 & 32.75 & 36.6 \\
\hline Tertiary & 5.58 & 4.76 & 7.39 & 3.13 & 2.15 & 5.74 & 5.01 & 3.96 & 7 \\
\hline
\end{tabular}

Source: authors' calculation using various rounds (2005, 2010, 2016/17) of Labour Force Survey (LFS).

In the case of paid employees, as expected, the proportion of workers with tertiary education was much higher (19.94 per cent in 2016/17) than that of general workers. The proportion of paid employees without any education was found to be 11.83 per cent in 2016/17. The highest proportion of workers (paid employees) were those with secondary education (47.76 per cent), followed by those with primary (20.47 per cent) and tertiary (19.94 per cent) education (Appendix Table A6). Over time, the proportion of paid employees with tertiary education has decreased (3.77 per cent in the entire period), with a corresponding increase in the proportion of workers with primary education (3.25 per cent increase). Therefore, for paid employees as well as for the entire labour force, we observe a shift from low education towards the secondary level of education.

Based on the one-digit ISCO-88 classification of skill groups, for 2016/17, the highest proportion of workers were found to be in skilled agriculture, forestry, and fishery (23.64 per cent), with other 
key sectors absorbing a large number of workers in elementary occupations (19.95 per cent) and craft and related trades (19.59 per cent) (Appendix Table A7). Looking at the changes that have occurred from 2005 to 2016/17, on the one hand, we can observe a noteworthy increase in craft and trade workers (10.38 per cent increase) which is expected mostly to be driven by increasing employment in the RMG sector, especially from 2010 to 2016/17. In 2016/17, almost one-fourth of the craft and trade workers were in RMG-related occupations. As for paid employees, the largest group was craft and trade workers as well and almost one-third of paid employees (29.14 per cent) were found to be in such occupations, with 60 per cent of workers employed in the RMG sector in 2016/17. On the other hand, there has been a reduction of those in skilled agriculture (8.61 per cent reduction for all workers and 2.87 per cent decline for paid employees). Therefore, a shift in occupational classification related to structural changes in the economy can be observed to some extent in the labour market as well. In the case of relatively high-skilled occupations (e.g., managerial jobs, professional occupations, etc.), we observe small changes for the entire workforce over the entire period. We also observe a systematic decline of professionals in both the time periods (i.e. 2005-10 and 2010-16/17), with a 10.08 per cent decline over the entire time period within the paid employee category (Appendix Table A8).A corresponding increase, although much smaller in magnitude for managers (5.46 per cent increase for paid employees and 1.41 per cent for the entire workforce) and technicians and associated professionals (3.7 per cent for paid employees and 2.88 per cent for the entire workforce), indicates a possible shift of the professional groups to either/both direction. One interesting thing to note in the case of the overall distribution of employment is that the changes in occupational classification have primarily taken place in the second stage of our analysis, with inter-occupational changes not being that strong in the first half of our analysis.

In terms of basic skill level of workers (high, medium, low), the highest proportion of paid employees (60.68 per cent) were found in mid-skilled occupations, the proportion of which has increased by a large margin over the years ( 11.54 per cent); the proportion of low-skilled workers, on the contrary, has decreased by a large margin (15.12 per cent). As for the two separate time periods (i.e. 2005-10 and 2010-16/17), we observe a fall in the proportion of those in mid-skilled occupations with a corresponding rise in the high- and mid-skilled groups, indicating a polarization of jobs at two extremes of skill distribution at least in the first period (see Section 5.3 for job polarization). This trend has almost reversed in the second period, with an increase in the proportion of both medium- and high-skilled workers and a fall in low-skilled workers (Table 2). The structure of skill component of paid employees also reflects high concentration of mid-skilled workers (60.58 per cent), followed by high-skilled (26.78 per cent) workers (Appendix Table A9).

Table 2: Distribution of workers by gender and occupation (\%)

\begin{tabular}{lccccccccc}
\hline Skill level & \multicolumn{3}{c}{ Male } & \multicolumn{3}{c}{ Female } & \multicolumn{3}{c}{ Total } \\
\cline { 2 - 10 } & 2005 & 2010 & $2016 / 17$ & 2005 & 2010 & $2016 / 17$ & 2005 & 2010 & $2016 / 17$ \\
\hline High & 5.48 & 6.56 & 8.46 & 4.86 & 3.77 & 10.37 & 5.33 & 5.7 & 8.91 \\
Medium & 40.88 & 39.85 & 50.79 & 19.76 & 23.32 & 36.78 & 35.95 & 34.77 & 47.49 \\
Low & 53.64 & 53.59 & 40.75 & 75.38 & 72.91 & 52.85 & 58.72 & 59.53 & 43.6 \\
\hline
\end{tabular}

Source: authors' calculation using various rounds $(2005,2010,2016 / 17)$ of LFS.

Detailed analysis as shown in relevant graphs also reflects an increase of those with medium skill. As shown in Appendix Figure A2, during the first phase of analysis we observed an increase in the proportion of those who are (i) low-skilled with secondary education and (ii) low-skilled with tertiary education in particular, and a decline in the proportion of those who are (i) mid-skilled with tertiary education, (ii) mid-skilled with secondary education, and (iii) low-skilled without any schooling. In the second phase, we observed an increase in the proportion of those who are (i) 
high-skilled with tertiary education (2010-16/17), (ii) mid-skilled with secondary education, and (iii) mid-skilled with primary education, and a decline in the proportion of those who are (i) lowskilled with tertiary education, (ii) mid-skilled with tertiary education, (iii) low-skilled with secondary education, and (iv) low-skilled with primary education. Thus, there has been an overall increase in the proportion of those with medium skill and with low- and mid-level education (primary and secondary education) as well as those with high skill and high-level education (tertiary education) and a decline in the proportion of those with low skill and low- and mid-level education (Appendix Figure A2).

Given the changes in skill-biased occupational distribution as in the one-digit ISCO classification, it is worth investigating the changed pattern in occupational classification in greater detail with more disaggregation. In Appendix Figure A3a, employment share as in the two-digit ISCO occupational classification shows that, in the first half of our analysis, the largest increase has been registered for certain occupations within the category of elementary occupation (two-digit ISCO classification of 92), which reversed in the second half with a decline in respective shares of that group. In the second half of our analysis, we observed an increase in the share of workers within the skilled agriculture group (61) along with those within craft and related trade $(73,71)$ and other mid-skilled occupations. Combining the results of these two time periods (2005-10 and 201016/17), for the entire timeframe of our analysis, we observed a sharp fall in certain low-skilled occupations with a moderate increase in the shares of certain mid-skilled occupations within craft and related trade $(74,73,72)$ and plant and machine operators $(83)$ in particular. For high-skilled occupations, some of the occupations $(12,33,32,34)$ experienced a small to moderate increase in their respective shares (Appendix Figure A3a). For paid employees (Appendix Figure A3b), we did not observe any sharp fall in any occupational share (according to the two-digit ISCO classification), rather a moderate fall in the shares of certain mid-skilled occupations $(51,41,82)$ and of certain high-skilled occupations (23). Some of the mid-skilled occupations (particularly 73) experienced a sharp rise in share compared with other high-skilled occupations $(13,33)$ which experienced a moderate rise in their respective shares.

\subsection{Distributional changes and task composition}

\section{Changes in the task content of occupations}

Changes in the occupational structure and shift of workers from low-skilled occupations to midand high-skilled occupations suggest a shift towards less routine-intensive occupations over time. We have found that average RTI has indeed fallen over time, particularly during the second period of our study (2010-16/17), for paid employees as well as for the entire workforce. This decline occurred regardless of whether we measured average RTI using O*NET or a country-specific measure. (Table 3).

Table 3: Average routine-task intensity (RTI), 2005-16/17

\begin{tabular}{lcccccc}
\hline RTI measure & \multicolumn{3}{c}{ All workers } & \multicolumn{3}{c}{ Paid employees } \\
\cline { 2 - 7 } & 2005 & 2010 & $2016 / 17$ & 2005 & 2010 & $2016 / 17$ \\
\hline Country-specific & 0.85 & 0.86 & 0.67 & 0.36 & 0.42 & 0.31 \\
O*NET & 0.28 & 0.43 & 0.29 & 0.18 & 0.33 & 0.11
\end{tabular}

Source: authors' calculation using various rounds (2005, 2010, 2016/17) of LFS.

To further explore the relationship of task content and changes in occupational structure and skill content, detailed graphical calculations were carried out following the approaches of Autor and Dorn (2013) and Firpo et al. (2011). In this section, distributions based on O*NET RTI index, survey RTI index, and country-specific RTI index across skill percentiles (ranked by 2005 
occupational mean wage) have been used (Appendix Figure A4, Figure 1, and Appendix Figure A5, respectively). Although not confirmative, the graphical analysis indicates-especially for paid employees - a decline in the share of routine manual tasks with an almost unchanged pattern of routine cognitive tasks. As expected, there is an overall increase in non-routine cognitive tasks and non-routine cognitive interpersonal tasks (Figure 2 and Appendix Figure A5, respectively). We also found a negative relationship between RTI and skill percentiles, implying that high-skilled workers are engaged in less routine-intensive tasks (Figure 2), with the pattern becoming stronger when measured with $\mathrm{O}^{*}$ NET RTI rather than country-specific RTI. Additionally, the RTI index is negative for O*NET after the 48th skill percentile whereas it is negative after the 88th percentile for the country-specific measure. Therefore, for the country-specific case, it takes more skill to have negative task content measures. In this context, the experience of Bangladesh has closely mirrored that of India (Vashisht and Dubey 2018) but is in contrast with that of the United States (Autor and Dorn 2009).

Figure 1: Country-specific RTI index (paid employees)

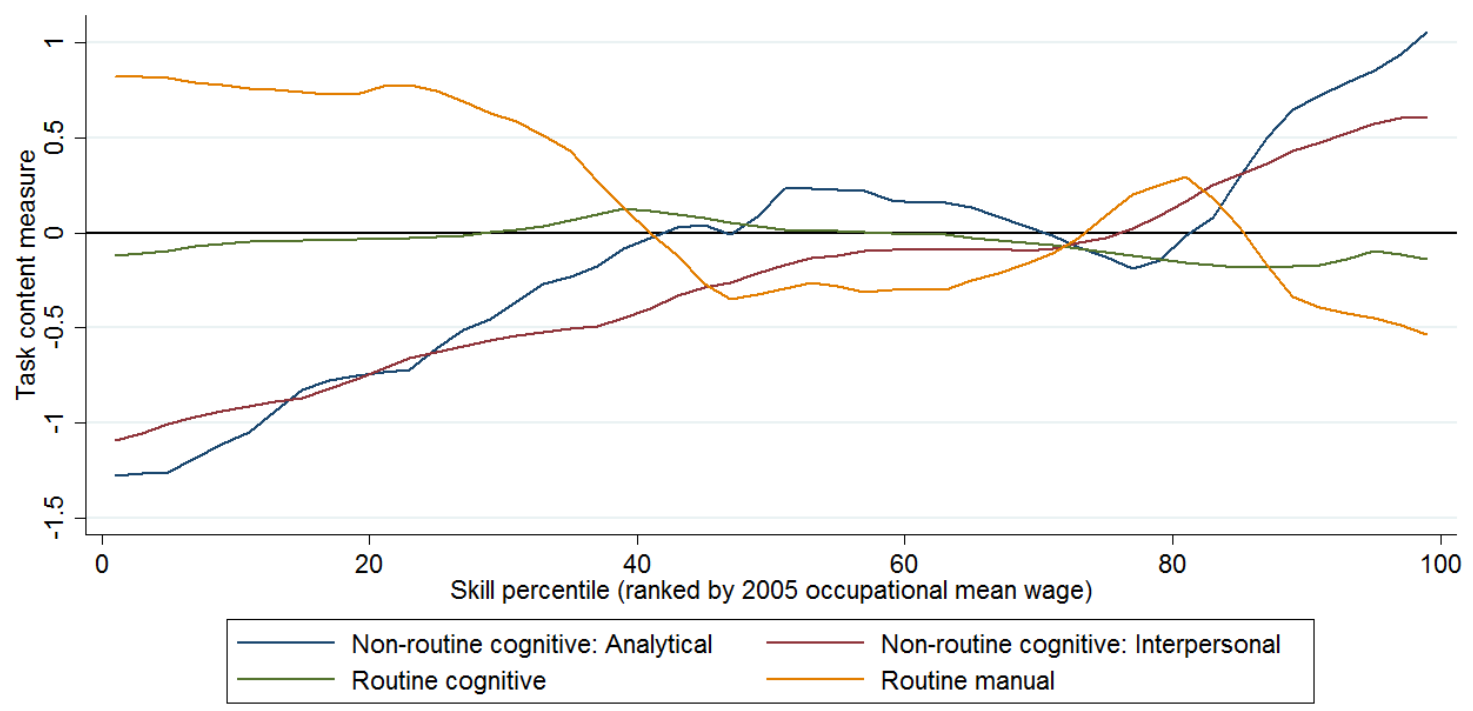

Source: authors' calculation using various rounds (2005, 2010, 2016/17) of Labour Force Survey (LFS).

Figure 2: RTI indices across skill percentages (paid employees)

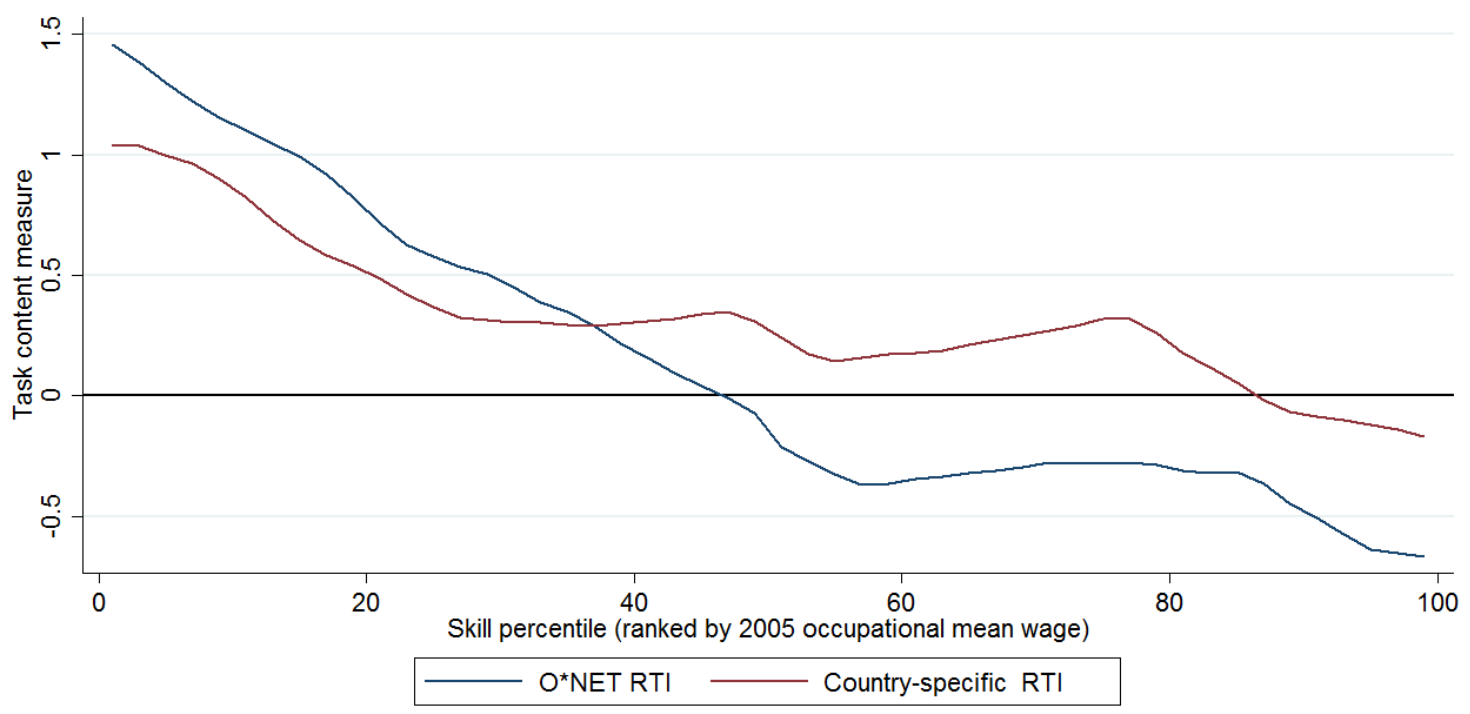

Source: authors' calculation using various rounds $(2005,2010,2016 / 17)$ of LFS. 
To understand any plausible impact of the changing nature of occupation due to changes in the production process on distribution of earnings, we have attempted to decompose different occupational classification in greater detail by the task content embodied in each occupation utilizing the information provided by $\mathrm{O}^{*} \mathrm{NET}$ data. In particular, following Sebastian (2018) we estimated the impact of O*NET RTI in its quadratic form on the three-digit occupational classification as well as country-specific RTI on the two-digit level on changes in employment and earnings, following the specification as described in Section 5.1.

Our ordinary least square estimates reflect no statistically significant evidence of a systematic relationship between employment share and RTI over the entire period; we found similar results for both O*NET RTI and country-specific RTI measures (Table 4). However, in case of estimation results focusing on changes in earnings, we found that earnings decline for occupations with higher routine-task content. The results become significant when the country-specific RTI measure is applied. Our results, therefore, are indicative of greater return towards more skilled and less routine-intensive works.

Table 4: Correlation between O*NET RTI and country-specific RTI measures and changes in employment and earnings, 2005-16/17 (all)

\begin{tabular}{|c|c|c|c|c|c|c|}
\hline \multirow[t]{2}{*}{ Variables } & \multicolumn{3}{|c|}{ Log change in employment share } & \multicolumn{3}{|c|}{ Change in log (mean) earnings } \\
\hline & $2005-10$ & $2010-16 / 17$ & $2005-16 / 17$ & $2005-10$ & $2010-16 / 17$ & $2005-16 / 17$ \\
\hline \multicolumn{7}{|l|}{ ONET*RTI variables } \\
\hline \multirow[t]{2}{*}{ ONET*RTI } & $0.909 *$ & 0.095 & 0.122 & $0.089 * \star$ & 0.005 & 0.128 \\
\hline & $(0.466)$ & $(0.183)$ & $(0.109)$ & $(0.041)$ & $(0.045)$ & $(0.082)$ \\
\hline \multirow[t]{2}{*}{ Square ONET*RTI } & -0.112 & 0.029 & -0.014 & $-0.042^{\star \star}$ & 0.011 & -0.029 \\
\hline & $(0.151)$ & $(0.094)$ & $(0.050)$ & $(0.018)$ & $(0.012)$ & $(0.025)$ \\
\hline \multirow[t]{2}{*}{ Constant } & $-0.848^{\star \star}$ & $-0.711^{*}$ & $-0.341^{\star \star \star}$ & $0.188^{\star * *}$ & $0.100^{* \star}$ & $0.218^{\star *}$ \\
\hline & $(0.417)$ & $(0.403)$ & $(0.122)$ & $(0.063)$ & $(0.040)$ & $(0.090)$ \\
\hline Observations & 108 & 106 & 106 & 107 & 102 & 103 \\
\hline Adjusted $R$-squared & 0.289 & -0.00870 & -0.00421 & 0.127 & -0.00701 & 0.138 \\
\hline \multicolumn{7}{|l|}{$\begin{array}{l}\text { Country-specific RTI } \\
\text { variables }\end{array}$} \\
\hline \multirow[t]{2}{*}{ Country-specific*RTI } & 0.645 & -0.546 & 0.344 & 0.018 & $-0.678^{\star \star \star}$ & -0.463 \\
\hline & $(1.106)$ & $(1.063)$ & $(0.651)$ & $(0.170)$ & $(0.184)$ & $(0.299)$ \\
\hline \multirow{2}{*}{$\begin{array}{l}\text { Square country-specific } \\
{ }^{*} \mathrm{RTI}\end{array}$} & -1.142 & 0.007 & -0.494 & 0.189 & $0.374^{\star \star}$ & 0.317 \\
\hline & $(1.475)$ & (1.117) & $(0.537)$ & $(0.207)$ & (0.159) & $(0.334)$ \\
\hline \multirow[t]{2}{*}{ Constant } & -0.215 & -0.174 & -0.164 & -0.015 & $0.365^{\star \star \star}$ & $0.342^{\star \star \star}$ \\
\hline & $(0.192)$ & $(0.243)$ & $(0.225)$ & $(0.045)$ & $(0.051)$ & $(0.049)$ \\
\hline Observations & 108 & 106 & 106 & 107 & 102 & 103 \\
\hline Adjusted $R$-squared & 0.0473 & 0.0191 & 0.00741 & 0.170 & 0.378 & 0.0285 \\
\hline
\end{tabular}

Note: robust standard errors in parentheses, ${ }^{*} p<0.01,{ }^{*} p<0.05,{ }^{*} p<0.1$.

Source: authors' calculation using various rounds (2005, 2010, 2016/17) of LFS.

\subsection{Changes in occupation structure and polarization of employment and earnings}

One of the key research interests of our study is to understand whether there has been any polarization of employment and earnings during our study period. Following Goos and Manning (2007), we applied a regression-based test of job and earnings polarization as described in Section 5.2. As shown in Table 5, in the first period of our analysis when we estimate log of change in employment share, we find a negative coefficient of log of hourly wage with the square term being 
positive. The sign of the coefficient estimates, however, shows an opposite scenario when we consider the estimation result in the second period. The results, therefore, indicate a U-shaped pattern of job polarization in Bangladesh only in the first period of our analysis (and only in the case of all workers), and over time we observe almost an opposite scenario of job polarization. Given the low (initial) skill base of the economy, it is quite plausible that although in the first period of our analysis there is a shift of workers towards opposite ends of the distribution, over time with greater accumulation of skills and/or due to the effect of off-shoring of jobs from developed countries, the proportion of mid-skilled workers increases (see Section 5.1). The trend is likely to continue in the near future because the overall skill base of workers is still at a low level, with high-skilled workers making up less than one-tenth (8.61 per cent in 2016/17) of the workforce.

Table 5: Correlation coefficients between change in log employment share and change in log of labour earnings (all versus paid)

\begin{tabular}{|c|c|c|c|c|c|c|}
\hline \multirow[t]{2}{*}{ Variables } & \multicolumn{3}{|c|}{ Log change in employment share } & \multicolumn{3}{|c|}{ Change in log (mean) earnings } \\
\hline & 2005-10 & $\begin{array}{l}2010- \\
16 / 17\end{array}$ & $\begin{array}{l}2005- \\
16 / 17\end{array}$ & 2005-10 & $\begin{array}{l}2010- \\
16 / 17\end{array}$ & $\begin{array}{l}2005- \\
16 / 17\end{array}$ \\
\hline \multicolumn{7}{|l|}{ All employment } \\
\hline \multirow{2}{*}{$\begin{array}{l}(\log ) \text { mean weekly earnings } \\
(t-1)\end{array}$} & $-50.423^{\star \star}$ & $68.937^{\star \star}$ & 9.835 & $-4.341^{\star \star}$ & $-9.571^{\star \star}$ & $-12.373^{\star \star \star}$ \\
\hline & $(24.492)$ & $(27.764)$ & (8.569) & $(1.820)$ & $(3.915)$ & $(2.985)$ \\
\hline \multirow{2}{*}{$\begin{array}{l}\text { Square (log) mean weekly } \\
\text { earnings }(t-1)\end{array}$} & $3.469 \star \star$ & $-4.595^{\star *}$ & -0.678 & $0.269 * \star$ & $0.664^{\star \star}$ & $0.844^{\star \star \star}$ \\
\hline & $(1.700)$ & $(1.874)$ & $(0.602)$ & $(0.129)$ & $(0.266)$ & $(0.209)$ \\
\hline \multirow[t]{2}{*}{ Constant } & $181.820 \star \star$ & $-258.256^{\star \star}$ & -35.858 & $17.362^{\star \star \star}$ & $34.591^{\star \star}$ & $45.393^{\star \star \star}$ \\
\hline & $(87.631)$ & $(102.524)$ & $(30.414)$ & $(6.416)$ & $(14.371)$ & $(10.591)$ \\
\hline Observations & 107 & 105 & 106 & 107 & 102 & 103 \\
\hline Adjusted $R$-squared & 0.268 & 0.232 & 0.00961 & 0.716 & 0.101 & 0.592 \\
\hline \multicolumn{7}{|l|}{ Paid employment } \\
\hline \multirow{2}{*}{$\begin{array}{l}(\text { Log) mean weekly earnings } \\
(t-1)\end{array}$} & $-23.191^{\star}$ & 10.845 & -10.685 & $-13.874^{\star \star \star}$ & $-13.506^{\star \star}$ & $-8.600 * \star$ \\
\hline & (11.833) & $(22.479)$ & $(9.226)$ & $(4.612)$ & $(6.356)$ & $(4.328)$ \\
\hline \multirow{2}{*}{$\begin{array}{l}\text { Square (log) mean weekly } \\
\text { earnings }(t-1)\end{array}$} & $1.513^{*}$ & -0.741 & 0.679 & 0.900 *** & $0.884^{\star *}$ & $0.596^{\star *}$ \\
\hline & $(0.793)$ & $(1.459)$ & $(0.622)$ & $(0.307)$ & $(0.413)$ & $(0.290)$ \\
\hline \multirow[t]{2}{*}{ Constant } & $88.383^{\star \star}$ & -40.399 & 41.135 & $53.327^{\star \star \star}$ & $51.587^{\star \star}$ & $31.037^{*}$ \\
\hline & $(44.087)$ & $(86.497)$ & $(34.111)$ & $(17.364)$ & $(24.396)$ & $(16.150)$ \\
\hline Observations & 99 & 96 & 102 & 99 & 96 & 102 \\
\hline Adjusted $R$-squared & 0.0218 & -0.00778 & -0.00476 & 0.172 & 0.0749 & 0.0678 \\
\hline
\end{tabular}

Note: robust standard errors in parentheses, ${ }^{* \star} p<0.01,{ }^{*} p<0.05,{ }^{*} p<0.1$.

Source: authors' calculation using various rounds $(2005,2010,2016 / 17)$ of LFS.

When considering log change in mean wage as the dependent variable, we found strong evidence of a U-shaped relationship. This result was consistently negative and significant in both of the periods, which is indicative of earnings polarization (further discussed in Section 5.4). Our regression-based polarization tests, therefore, confirm earnings polarization in Bangladesh but not job polarization.

\subsection{Distribution of earnings of workers by education and skill levels}

In terms of earnings of workers, the inflation-adjusted data shows an overall increase in earnings for all education groups, with the highest increase experienced by those at two extreme ends of 
the distribution of education: those with tertiary education (5.52 per cent increase) and those without any formal education (3.42 per cent increase) (Table 6). As for the earnings of paid employees, although there has been an overall increase in earnings, those with tertiary education experienced the highest increase (5.65 per cent increase) as expected, with those without any education experiencing a slight decline in earnings in real term (Appendix Table A10).

Table 6: Real mean earnings by gender and level of education (in BDT)

\begin{tabular}{lccccccccc}
\hline Highest class passed & \multicolumn{3}{c}{ Male } & \multicolumn{3}{c}{ Female } & \multicolumn{3}{c}{ Total } \\
\cline { 2 - 10 } & 2005 & 2010 & $2016 / 17$ & 2005 & 2010 & $2016 / 17$ & 2005 & 2010 & $2016 / 17$ \\
\hline No schooling & 938 & 1,234 & 1,371 & 842 & 1,313 & 1,243 & 922 & 1,244 & 1,335 \\
Primary & 1,215 & 1,417 & 1,481 & 1,184 & 1,372 & 1,450 & 1,211 & 1,413 & 1,475 \\
Secondary & 1,664 & 1,887 & 1,997 & 1,629 & 1,554 & 1,968 & 1,660 & 1,850 & 1,991 \\
Tertiary & 2,377 & 3,769 & 4,440 & 2,432 & 2,552 & 3,858 & 2,387 & 3,612 & 4,310 \\
Total & 1,342 & 1,611 & 1,981 & 1,276 & 1,468 & 1,821 & 1,332 & 1,594 & 1,943 \\
\hline
\end{tabular}

Note: BDT, Bangladeshi taka.

Source: authors' calculation using various rounds $(2005,2010,2016 / 17)$ of LFS.

A number of studies over the past decades have explored returns to education for different countries (Psacharopoulos 1972, 1981, 1985, 1993, 1994, 2006; Psacharopoulos and Patrinos 2018; Patrinos and Psacharopoulos 2002, 2011, 2020). From these studies, we can notice a pattern of private returns to primary education being higher but these returns are found to be declining moderately over time. In addition, an increase in private returns to higher education, especially for low- and mid-income countries, can be witnessed during these four decades (1970s, 1980s, 1990s, and 2000s). To better understand the linkages between education and earnings and the trend of education premium, we utilized a parametric method as explained in Section 5.3. Here, in the first step, we estimated the models while controlling only for education (Appendix Figure A6) and then in the next step added other controls (Appendix Figure A7). In the third specification, we included occupation dummies (two-digit ISCO-88 codes). Finally, we attempted to compare the coefficient estimates of education categories (education premium) across survey waves for male and female sexes (Figure 3).

Figure 3: Education premium on log earnings (regression 3): (a) male and (b) female

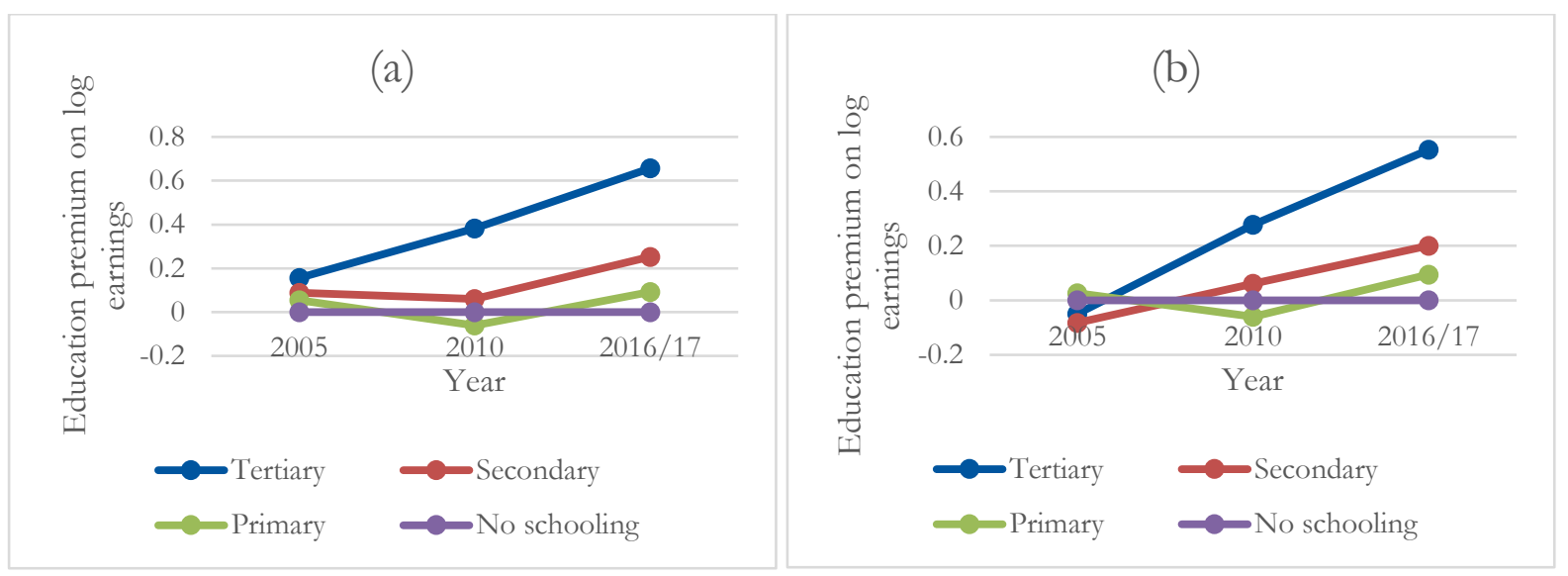

Source: authors' calculation using various rounds (2005, 2010, 2016/17) of LFS.

In the first two sets of graphs (Appendix Figures A6 and A7), we do not observe much difference and the trend and pattern do not differ much across the sexes either. In the third set of graphs (Figure 3), which are probably the most comprehensive ones incorporating the effects of other 
relevant covariates, we find a significant effect of gender on returns to education. Considering these, it can be inferred that (i) for those holding a degree in tertiary education, education premium was highest and increased consistently for both the sexes; (ii) for those with secondary education, although there is consistent increment for women, for men education premium only registered an increase in the second half of our analysis; and (iii) for those with primary education, for both gender, education premium declined in the first half but registered an increase in the second half.

In terms of returns to skill of workers, comparing the three waves of inflation-adjusted mean weekly earnings for one-digit ISCO-88 occupation groups, we observe an increase in real earnings for all occupational groups. However, in a clear indication of earnings polarization, we find that the largest increase is registered for high-skilled workers (e.g., managers, 4.79 per cent; professionals, 4.44 per cent), followed by low-skilled workers (e.g., those in skilled agriculture, forestry, and fishery, 2.80 per cent; workers involved in elementary occupations, 3.35 per cent). Mid-skilled workers experienced a comparatively moderate increase in earnings (Table 7 and Appendix Table A11). For paid employees, although employees of most of the skill levels experienced a rise, a number of mid-skilled and low-skilled workers (e.g., service and sales workers, craft and trade workers, skilled agriculture workers, and those in elementary occupations) experienced a small decline in their real earnings over time (Appendix Table A12). ${ }^{8}$ A detailed analysis of two-digit ISCO classification over the entire timeframe (2005-16/17) for paid employees also shows that earnings of most of the high-skilled occupation groups (two-digit ISCO classification of $12,22,21,23,24,13,31,32,33,34)$ some of the mid-skilled jobs $(42,41,51,83)$, and those in low-skilled elementary occupation (92) experienced a rise in earnings (Appendix Figure A8a). As for the entire workforce, as shown in Appendix Figure A8b, the highest rise in mean earnings was experienced by high-skilled occupation groups (two-digit ISCO classification of $12,21,13,23,24,22,33)$ along with several low-skilled occupational categories $(92,93,91,62)$ and mid-skilled occupational groups $(74,73,72,83,81)$.

Table 7: Real mean weekly earnings by gender and skill level (in BDT)

\begin{tabular}{lccccccccc}
\hline Skill & \multicolumn{3}{c}{ Male } & \multicolumn{3}{c}{ Female } & \multicolumn{3}{c}{ Total } \\
\cline { 2 - 10 } & 2005 & 2010 & $2016 / 17$ & 2005 & 2010 & $2016 / 17$ & 2005 & 2010 & $2016 / 17$ \\
\hline High & 2,399 & 2,843 & 4,035 & 2,265 & 2,065 & 3,372 & 2,366 & 2,701 & 3,841 \\
Medium & 1,643 & 1,793 & 1,861 & 1,232 & 1,498 & 1,655 & 1,572 & 1,753 & 1,814 \\
Low & 910 & 1,258 & 1,324 & 823 & 1,214 & 1,143 & 901 & 1,254 & 1,284 \\
Total & 1,342 & 1,611 & 1,981 & 1,276 & 1,468 & 1,821 & 1,332 & 1,594 & 1,943 \\
\hline
\end{tabular}

Source: authors' calculation using various rounds (2005, 2010, 2016/17) of LFS.

\subsection{Distribution of earnings and task content}

Appendix Figure A9 has attempted to understand RTI based on earnings percentile and revealed that, with certain exceptions at the top percentiles, the country-specific RTI measure is negatively correlated with earnings percentiles. The relationship, when measured with respect to $\mathrm{O} * \mathrm{NET}$ RTI, becomes weaker. However, the concentration of routine tasks is still higher at the bottom percentiles and declines sharply at the top across all waves. In the first wave, the relationship exhibits an inverse U-shaped pattern, with routine-intensive occupations dominating the middle part of the earnings distribution. In the second and third waves, RTI does not appear to change significantly with earnings (first half of the distribution), but it does decline at the top half of the

\footnotetext{
${ }^{8}$ Due to coding differences across the three waves of LFS, we could not separately calculate earnings for RMG workers. It is unlikely that RMG workers' wages have declined over time, particularly with increases in minimum wage over time.
} 
distribution for all three data points, with the top deciles getting a larger share of income. Furthermore, we observe that in the first sub-period, the share of income decreased for the bottom to mid-deciles and increased for the top deciles, with the highest increase occurring for the topmost decile. Given that the magnitude of these changes is low, they do not contribute to any significant increase in inequality; thus, inequality as measured by the Gini index remained almost constant during this period. However, in the second sub-period (2010-16), we see the opposite pattern: the share of income increased for the lower deciles, decreased for the mid-deciles, and increased only slightly in the topmost deciles. Overall, this pattern contributed to a decrease in inequality during this period. Curiously, if we consider the entire period, we observe that share of income fell for almost all decile except for topmost deciles. However, given that the decrease in mid- and top deciles is more pronounced, this is likely to have contributed to a decrease in inequality during the overall period (Appendix Figures A10 and A11).

The inter-quantile ratio between the poorest and richest segments as well as between the middleincome and poorest groups has consistently gone down over time for all of paid workers (Appendix Table A13). The trend for paid employees, however, reflects an increase in such ratios in the first period. Based on Gini indices, between 2005 and 2010, we do not observe much change in earnings inequality; however, comparing 2010 and 2016/17 indices, we can see a decline in Gini for earnings (Table 8). A similar trend of declining inequality between 2010 and 2016/17 can be seen in case of the variance of log earnings as well (Table 9). The Lorenz curve of earnings for all the three datasets also shows that, in terms of earnings inequality, there have not been many changes over time, with the Lorenz curves lying very close to each other (Appendix Figure A12).

Table 8: Commonly used inequality indices (all workers)

\begin{tabular}{llcc}
\hline & 2005 & 2010 & $2016 / 17$ \\
Variance & 0.512 & 0.397 & 0.309 \\
Gini In & 0.057 & 0.049 & 0.039 \\
Gini & 0.368 & 0.370 & 0.320 \\
\hline
\end{tabular}

Source: authors' calculation using various rounds $(2005,2010,2016 / 17)$ of LFS.

Table 9: Inter-quantile ratios (all workers)

\begin{tabular}{lccc}
\hline & 2005 & 2010 & $2016 / 17$ \\
\hline $\ln (q 90)-(q 10)$ & 1.83 & 1.54 & 1.20 \\
$\ln (q 90)-(q 50)$ & 0.98 & 0.85 & 0.80 \\
$\ln (q 50)-(q 10)$ & 0.85 & 0.69 & 0.41
\end{tabular}

Source: authors' calculation using various rounds $(2005,2010,2016 / 17)$ of LFS.

The growth incidence curves do not reflect high inequality and, at least in the second part of our analysis, we observe moderate growth in earnings at the bottom of the distribution (Appendix Figure A11). In the first half of our analysis, earnings growth was quite low across the entire distribution and those in the middle of the distribution primarily experienced average growth in earnings, with an equal distributional pattern at both ends of the distribution.

From growth incidence curve bar graphs, we observe that, during the first sub-period, workers in the middle of the distribution had almost no fluctuation in earnings. However, with the exception of the topmost percentiles, those at the upper percentiles fell below average. Although one would expect a larger decline in income inequality during the first sub-period based on the inter-quantile ratios (Table 9), this polarizing trend of above-average income at the bottom and, to a lesser extent, the topmost percentiles, is likely to explain the rather slight increase in inequality observed in the first sub-period. The lower tail started from higher than the average and then fell below average. For the second sub-period (2010-16/17), there is a clear pro-poor growth pattern, resulting in 
inequality declining strongly in 2016/17. For the entire period (2005-16/17), a pro-poor growth pattern is visible and reflects the fall in inequality observed (Figure 4).

Figure 4: Growth incidence curves bar (all)

\section{Annual average growth rate of real earnings}
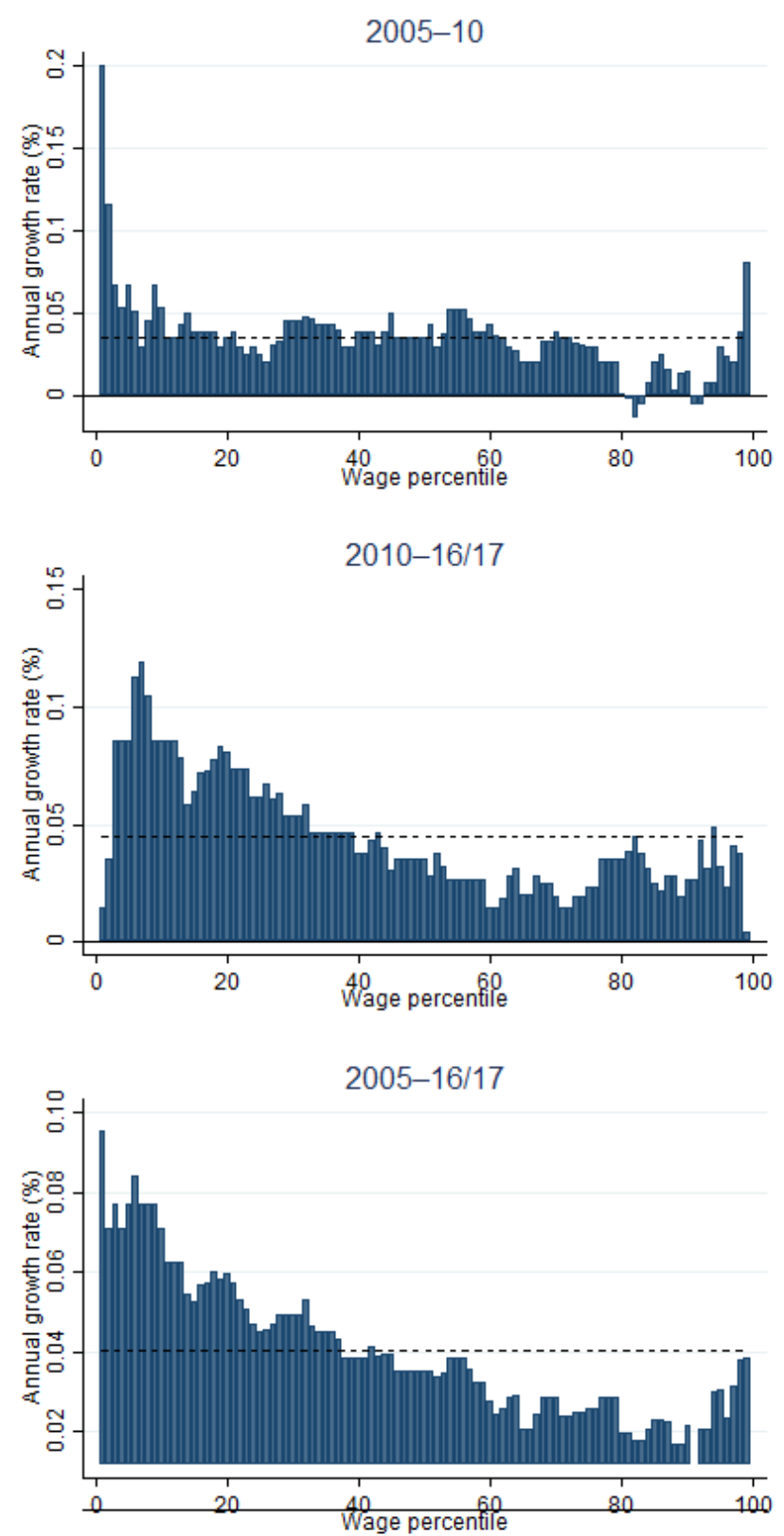

Source: authors' calculation using various rounds (2005, 2010, 2016/17) of LFS.

For paid workers, we see the opposite trend: a clear pro-rich growth pattern in the first sub-period, reflecting a rise in inequality. In the second sub-period, the mid-income range remained fairly stable around the mean growth rate whereas the lower tail of the distribution started significantly above the mean growth rate but eventually fell below average. The upper tail started below average and then rose above. This pattern indicates a marginal decline in inequality. During the entire period, the middle-income group experienced stable and below-average earnings. The distribution as a whole shows a pro-rich growth pattern, with the upper tail experiencing above-average growth compared with the lower tail group, reflecting the rise in inequality from 2005 to 2016/17. 


\subsection{Decomposition analysis}

As discussed in Section 4, in addition to knowing the pattern of inequality over time, we apply appropriate decomposition techniques to identify the factors that have been acting as key drivers of inequality. We decompose the earnings inequality as measured by the Gini index between the two sub-periods: 2005-10 and 2010-16/17 using Shapley decomposition and RIF decomposition.

\section{Shapley decomposition}

In this paper, we are interested in the role of tasks performed by workers in their respective jobs in explaining the observed trend in inequality. There is a growing body of literature focusing on the fact that differences between occupations do not account for the entire differentials in skill requirements and productivity but can also be affected by other job characteristics, such as working conditions and the type of tasks. If changes in earnings of certain occupations are responsible for the patterns in earnings inequality, this can be reflected in the gap in average earnings between occupations. In contrast, if inequality changes are driven by factors other than the characteristics of occupations, this can be reflected in within-occupation inequality, driving the pattern of overall earnings inequality (Gradín and Schotte 2020).

From Table 10 we can infer that differences in average earnings across occupations (i.e. betweenoccupation differences) could explain a sizeable portion (41 per cent) of overall earnings inequality in 2005. However, over time this share has fallen significantly, with within-occupation differences accounting for almost three-fourths of the overall earnings inequality (74 per cent) in 2010. Keeping in mind the changes in employment shares of different skill groups, we can infer that factors other than earnings and job characteristics must have driven the trend in inequality during the first sub-period. During the second sub-period of our study, inequality fell significantly and the between-occupation effect became important once again, explaining more than half of the total earnings inequality (51 per cent). During 2010-16/17, the share of employment in mid-skilled occupations increased significantly, with a strong decline in the share of low-skilled jobs and a moderate increase in high-skilled jobs. In terms of earnings, during this period, high-skilled workers experienced the highest increase in average earnings. In this context, as the share of highskilled workers is quite low (around 8 per cent), the trend in inequality is most likely to be driven by changes in mid-skilled occupations. Other factors such as education and information asymmetry between workers and employers might have also played an important role in increasing frictions in the labour market. Therefore, within-occupation factors not directly related to changes in average earnings have continued to be important in explaining overall inequality in Bangladesh. Our findings are robust across alternative specifications where we have disaggregated occupations to the three-digit level (Appendix Table A14).

Table 10: Gini index decomposed into between- and within-occupation inequality

\begin{tabular}{lccccccccc}
\hline & \multicolumn{3}{c}{ Actual } & \multicolumn{3}{c}{ Shares constant } & \multicolumn{3}{c}{ Means constant } \\
\cline { 2 - 11 } & 2005 & 2010 & $2016 / 17$ & 2005 & 2010 & $2016 / 17$ & 2005 & 2010 & $2016 / 17$ \\
\hline Overall Gini & 0.3677 & 0.3698 & 0.3198 & 0.3677 & 0.3571 & 0.3092 & 0.3677 & 0.3915 & 0.3004 \\
Shapley decomposition & & & & & & & & & \\
$\quad$ Between-occupation & 0.1491 & 0.0975 & 0.1615 & 0.1491 & 0.0999 & 0.152 & 0.1491 & 0.1343 & 0.1373 \\
$\quad$ \% Ratio & 41 & 26 & 51 & 41 & 28 & 49 & 41 & 34 & 46 \\
$\quad$ Within-occupation & 0.2186 & 0.2723 & 0.1583 & 0.2186 & 0.2572 & 0.1572 & 0.2186 & 0.2572 & 0.1631 \\
\% Ratio & 59 & 74 & 49 & 59 & 72 & 51 & 59 & 66 & 54
\end{tabular}

Source: authors' calculation using various rounds $(2005,2010,2016 / 17)$ of LFS.

Moreover, following Gradín and Schotte (2020), we separate the direct role of changes in the composition of employment by occupation from the role of changes in mean earnings by 
occupations in order to more specifically identify the drivers behind the fall in inequality between occupations. As explained in Section 4.2 and the Methodological Appendix, we do this by analysing two counterfactual situations. In one specification we hold occupation shares constant, whereas in the other we hold mean earnings constant. The Shapley decomposition results are reported in Table 11.

Table 11: Change in the Gini index decomposed into the contribution of changes in employment shares and in mean earnings (Shapley decomposition based on Table 10), 2005-16/17

\begin{tabular}{lccc}
\hline & $2005-10$ & $2010-16 / 17$ & $2005-16 / 17$ \\
\hline Change in employment shares (mean earnings constant) & -0.009 & 0.025 & 0.016 \\
Change in mean earnings (employment shares constant) & -0.043 & 0.039 & -0.004 \\
Total change & -0.052 & 0.064 & 0.012 \\
\hline
\end{tabular}

Source: authors' calculation using various rounds $(2005,2010,2016 / 17)$ of LFS.

Our findings show that, in the first sub-period, the tightening of the gap in average earnings across occupations is mostly responsible for the fall in between-occupation inequality. As a result, we observe an equality-enhancing effect associated with changes in the reward of job characteristics, such as skills and tasks on the labour market. Furthermore, changes in employment shares across occupations also help explain the decline in between-occupation inequality. Therefore, shifts in the structure of employment across occupations helped decrease inequality (Table 11). On the other hand, in the second sub-period, both changes in average earnings and changes in employment shares across occupations have an inequality-enhancing effect and help explain the rise in between-occupation inequality. This finding is also robust across alternative specifications, where we disaggregated occupations to the three-digit level (Appendix Table A15). If we consider the overall survey period, Table 11 further suggests that changes in employment shares had a disequalizing effect whereas changes in mean earnings across occupations had a slightly equalizing effect, resulting in an overall increase in between-occupation inequality.

We further decompose the decline in inequality between occupations into the contribution of changes in mean earnings (holding occupation shares constant with 2005 as the reference period) and in occupation shares (holding mean earnings constant with 2005 as the reference period). The first contribution reflects the change in inequality that is associated with changes in the returns to job characteristics (e.g., skills and tasks) on the labour market, whereas the second reflects the effect on the inequality of changes in the employment composition (e.g., movements of workers towards higher-skilled and less routine-intensive occupations). Notably, in case of a 'means constant' case, we find that the explanatory share of within-occupation effect became even stronger in 2016/17.

In Table 12, the results of isolating the effect of RTI (i.e. the extent to which the degree of the routinization of occupations is associated with this decline in earnings inequality between occupations) have been shown using concentration index. This index measures the extent to which average earnings of occupations tend to systematically increase in jobs with less routine-intensive tasks (Gradín and Schotte 2020). As reflected in Table 12, the roles of RTI and average earnings of occupations in explaining inequality are quite similar, accounting for about 72-90 per cent of between-occupation inequality. This finding is even more pronounced in the first and third survey waves of the analysis. The somewhat weaker relationship in 2010 can perhaps be explained by the possibility of average earnings being less relevant in explaining inequality in that year. 
Table 12: Concentration index, 2005-16/17

\begin{tabular}{cccccccccc}
\hline & \multicolumn{3}{c}{ Actual } & \multicolumn{3}{c}{ Shares constant } & \multicolumn{3}{c}{ Means constant } \\
\cline { 2 - 10 } & 2005 & 2010 & $2016 / 17$ & 2005 & 2010 & $2016 / 17$ & 2005 & 2010 & $2016 / 17$ \\
\hline Gini between occupations & 0.2215 & 0.1584 & 0.2239 & 0.2215 & 0.1612 & 0.2117 & 0.2215 & 0.2103 & 0.1949 \\
Concentration index & & & & & & & & & \\
RTI (country-specific) & 0.1959 & 0.114 & 0.2004 & 0.1959 & 0.1253 & 0.1928 & 0.1959 & 0.1758 & 0.1713 \\
\% Ratio & 88 & 72 & 90 & 88 & 78 & 91 & 88 & 84 & 88 \\
RTI (O*NET) & 0.1072 & 0.1128 & 0.1611 & 0.1072 & 0.1085 & 0.1413 & 0.1072 & 0.0999 & 0.1048 \\
\% Ratio & 48 & 71 & 72 & 48 & 67 & 67 & 48 & 48 & 54 \\
\hline
\end{tabular}

Source: authors' calculation using various rounds $(2005,2010,2016 / 17)$ of LFS.

Furthermore, comparing the corresponding figures of country-specific RTI with those of O*NET RTI, we observe that significant differences across occupation rankings in the first wave (2005) exist based on corresponding concentration ratios (varies between 88 per cent using the countryspecific measure and 48 per cent using $\mathrm{O}^{*} \mathrm{NET}$ ). The country-specific measure suggests that the relationship between RTI and average earnings in explaining between-occupation inequality grew weaker over the first sub-period, although there was an increase in rank correlation between earnings and O*NET RTI measure. However, during the second sub-period as well as the entire period, the correlation increased based on both measures (to a ratio of 90 and 72 per cent, respectively), suggesting that the relationship between the RTI of occupations and average earnings strengthened over time.

\section{RIF decomposition}

Although the Shapley decomposition technique is useful in explaining earnings inequality through between- and within-occupation components, it does not shed light on the contribution of individual factors on inequality. In this connection, as discussed in Section 4.2, the RIF regression decomposition technique helps us to explore the role of routine-task content in the trend in inequality and helps us to isolate its impact. This method also helps to examine the channel through which the effect is transmitted, that is, whether through the characteristics of employment (composition effect) or the returns to these characteristics (structure effect).

Our RIF decomposition analysis shows that the changes in demographic characteristics like age, gender, level of education, or the change in the composition of routine-task content of occupations do not explain the trend in earnings inequality in Bangladesh. This has been witnessed during both the sub-periods of 2005-10 and 2010-16/17, where the composition effect of educational attainment was found to be dis-equalizing whereas the effect of RTI (i.e. the structure of employment) was equalizing at the first sub-period. According to our analysis, it is the earnings structure effect that explains the trend in inequality during both of the sub-periods. Earnings structure effect of education was found to be equalizing for the first sub-period and dis-equalizing for the second one in both the country-specific and O*NET RTI measures. Both O*NET and country-specific RTI measures show the earnings structure effect of RTI having an equalizing effect in the first sub-period but a dis-equalizing effect in the second period (Table 13). If we use the $\mathrm{O} *$ NET measure, then the effects are equalizing in both cases. For both of the sub-periods, the growth of education premium was inequality reducing. For changes in routine versus nonroutine tasks, if measured by $\mathrm{O}^{*} \mathrm{NET}$, it was inequality reducing; if measured by the countryspecific measures, it was rather inequality inducing during the first sub-period but inequality reducing for the second. 
Table 13: RIF regression decomposition (earnings)

\begin{tabular}{|c|c|c|c|c|c|c|}
\hline & \multicolumn{3}{|c|}{ RTI (country-specific) } & \multicolumn{3}{|c|}{ RTI O*NET } \\
\hline & 2005-10 & 2010-16/17 & 2005-16/17 & 2005-10 & 2010-16/17 & 2005-16/17 \\
\hline \multicolumn{7}{|l|}{ Distribution } \\
\hline \multirow[t]{2}{*}{ Final $F$} & 0.403 & 0.354 & 0.354 & 0.403 & 0.354 & 0.354 \\
\hline & $(0.002)$ & $(0.001)$ & $(0.002)$ & $(0.002)$ & $(0.001)$ & $(0.002)$ \\
\hline \multirow[t]{2}{*}{ Initial / } & 0.359 & 0.403 & 0.359 & 0.359 & 0.403 & 0.359 \\
\hline & $(0.015)$ & $(0.008)$ & $(0.002)$ & $(0.015)$ & $(0.008)$ & $(0.002)$ \\
\hline \multirow[t]{2}{*}{ Total change $(F-l)$} & 0.044 & -0.049 & -0.005 & 0.044 & -0.049 & -0.005 \\
\hline & $(0.017)$ & $(0.008)$ & $(0.005)$ & $(0.017)$ & $(0.008)$ & $(0.005)$ \\
\hline \multicolumn{7}{|l|}{$\begin{array}{l}\text { Reweighting } \\
\text { decomposition }\end{array}$} \\
\hline \multirow[t]{2}{*}{ Counterfactual $C$} & 0.362 & 0.406 & 0.358 & 0.364 & 0.405 & 0.356 \\
\hline & $(0.011)$ & $(0.008)$ & $(0.006)$ & $(0.011)$ & $(0.009)$ & $(0.005)$ \\
\hline \multirow[t]{2}{*}{ Total composition $C-I$} & 0.002 & 0.002 & -0.001 & 0.005 & 0.002 & -0.004 \\
\hline & $(0.004)$ & $(0.000)$ & $(0.004)$ & $(0.004)$ & $(0.002)$ & $(0.002)$ \\
\hline \multirow{3}{*}{$\begin{array}{l}\text { Total earnings structure } \\
F-C\end{array}$} & 0.041 & -0.051 & -0.004 & 0.039 & -0.051 & -0.002 \\
\hline & & & & & & \\
\hline & $(0.013)$ & $(0.008)$ & $(0.008)$ & $(0.013)$ & $(0.010)$ & $(0.007)$ \\
\hline \multicolumn{7}{|l|}{ RIF composition } \\
\hline \multirow[t]{2}{*}{ Age } & 0.000 & 0.000 & 0.000 & 0.000 & 0.000 & 0.000 \\
\hline & $(0.001)$ & $(0.001)$ & $(0.000)$ & $(0.001)$ & $(0.001)$ & $(0.000)$ \\
\hline \multirow[t]{2}{*}{ Sex } & 0.003 & -0.001 & 0.005 & 0.003 & -0.001 & 0.004 \\
\hline & $(0.002)$ & $(0.000)$ & $(0.004)$ & $(0.002)$ & $(0.000)$ & $(0.004)$ \\
\hline \multirow[t]{2}{*}{ Education } & 0.001 & 0.008 & -0.002 & 0.002 & 0.010 & -0.003 \\
\hline & $(0.002)$ & $(0.003)$ & $(0.000)$ & $(0.003)$ & $(0.002)$ & $(0.000)$ \\
\hline \multirow[t]{2}{*}{ Religion } & 0.001 & 0.002 & 0.000 & 0.001 & 0.002 & 0.000 \\
\hline & $(0.000)$ & $(0.002)$ & $(0.001)$ & $(0.000)$ & $(0.002)$ & $(0.001)$ \\
\hline \multirow[t]{2}{*}{ RTI } & -0.002 & 0.000 & -0.002 & 0.001 & -0.003 & -0.002 \\
\hline & $(0.002)$ & $(0.002)$ & $(0.001)$ & $(0.001)$ & $(0.001)$ & $(0.000)$ \\
\hline \multirow[t]{2}{*}{ Explained } & 0.003 & 0.008 & 0.001 & 0.006 & 0.007 & -0.001 \\
\hline & $(0.005)$ & $(0.001)$ & $(0.002)$ & $(0.005)$ & $(0.003)$ & $(0.002)$ \\
\hline \multicolumn{7}{|l|}{ RIF earnings structure } \\
\hline \multirow[t]{2}{*}{ Age } & 0.011 & 0.001 & 0.014 & 0.010 & 0.000 & 0.017 \\
\hline & $(0.011)$ & $(0.007)$ & $(0.000)$ & $(0.009)$ & $(0.009)$ & $(0.001)$ \\
\hline \multirow[t]{2}{*}{ Sex } & -0.012 & 0.016 & -0.002 & -0.010 & 0.014 & 0.001 \\
\hline & $(0.005)$ & $(0.004)$ & $(0.010)$ & $(0.003)$ & $(0.004)$ & $(0.007)$ \\
\hline \multirow[t]{2}{*}{ Education } & -0.040 & 0.023 & -0.018 & -0.045 & 0.028 & -0.007 \\
\hline & $(0.013)$ & $(0.006)$ & $(0.006)$ & $(0.010)$ & $(0.002)$ & $(0.007)$ \\
\hline \multirow[t]{2}{*}{ Religion } & -0.005 & 0.001 & -0.001 & -0.006 & 0.002 & -0.002 \\
\hline & $(0.004)$ & $(0.000)$ & $(0.004)$ & $(0.005)$ & $(0.001)$ & $(0.004)$ \\
\hline \multirow[t]{2}{*}{$\mathrm{RTI}$} & 0.021 & -0.056 & -0.037 & -0.026 & 0.007 & -0.016 \\
\hline & $(0.023)$ & $(0.009)$ & $(0.004)$ & $(0.001)$ & $(0.000)$ & $(0.001)$ \\
\hline Constant & 0.066 & -0.036 & 0.041 & 0.115 & -0.098 & 0.006 \\
\hline & $(0.012)$ & $(0.001)$ & $(0.004)$ & $(0.008)$ & $(0.007)$ & $(0.011)$ \\
\hline Unexplained & 0.041 & -0.051 & -0.003 & 0.039 & -0.048 & -0.002 \\
\hline & $(0.013)$ & $(0.007)$ & $(0.008)$ & $(0.013)$ & $(0.009)$ & $(0.008)$ \\
\hline
\end{tabular}

Note: bootstrap standard errors in parentheses; number of replications: 100.

Source: authors' calculation using various rounds (2005, 2010, 2016/17) of LFS. 
In this analysis, RIF decomposition has been applied to decompose changes in earnings over time across different quantiles. The results reflect that the earnings structure effect primarily dominates the total change in earnings in both of the sub-periods across the entire distribution (see Figure 5). We deduce that for the first sub-period (2005-10) the detailed decomposition of earnings structure effect (country-specific measure) suggest a pro-rich profile of the change in RTI whereas the effect of education is not entirely pro-rich for the first sub-period as the effects are found to be negative for the uppermost percentiles of the distribution(see Figure 6). For the second sub-period, we observe a pro-poor feature of the RTI. During this period, education accounts for decreasing inequality for most of the upper tail of the distribution. So, during the second sub-period we witness a combined effect of returns to education and RTI on the decline in inequality.

Figure 5: RIF decomposition (country-specific): (a) 2005-10; (b) 2010-16/17

(a)

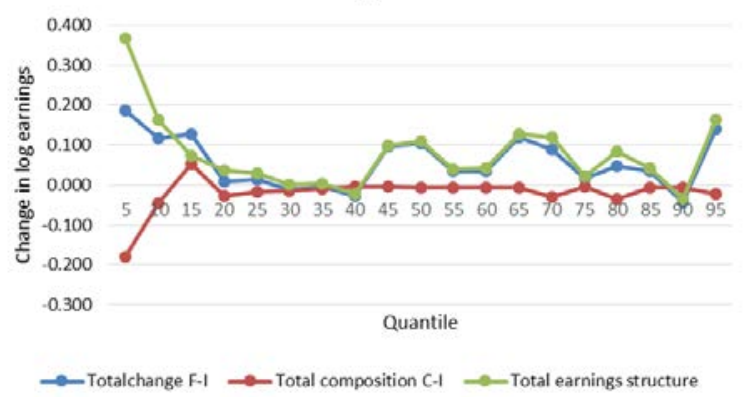

(b)

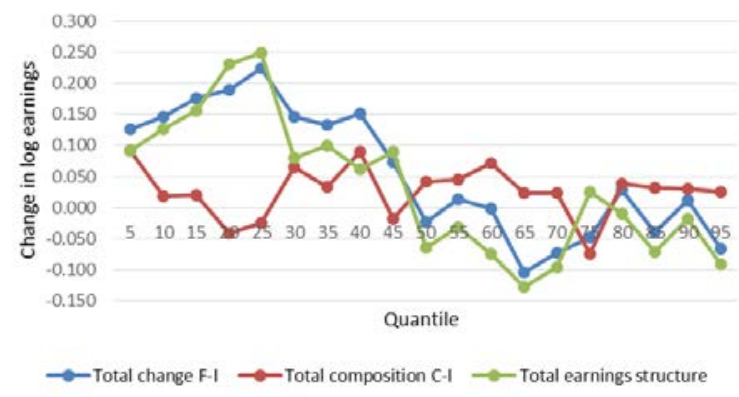

Source: authors' calculation using various rounds (2005, 2010, 2016/17) of LFS.

Figure 6: Detailed RIF decomposition of earnings structure: (a) 2005-10; (b) 2010-16/17

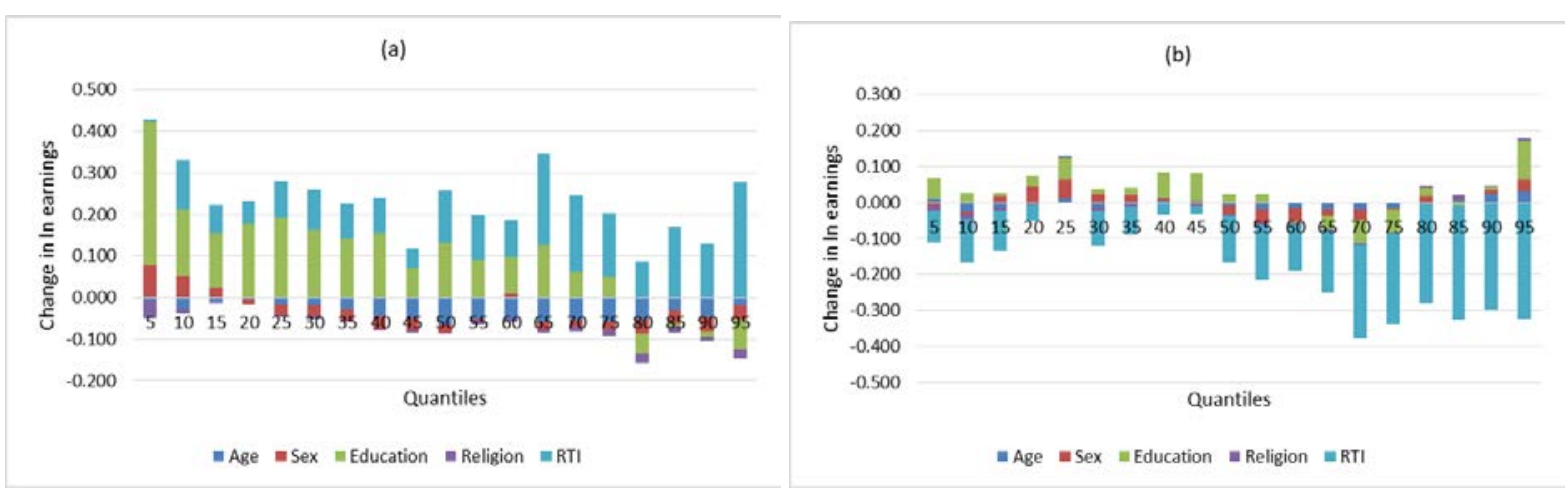

Source: authors' calculation using various rounds (2005, 2010, 2016/17) of LFS.

\section{Summary of results and recommendations:}

Utilizing three cross-sections of nationally representative survey data of Bangladesh and combining those with the O*NET data, this paper has applied a number of quantitative tools to understand the way technological change and RTI has affected earnings distribution in Bangladesh. Our analysis has revealed of the following findings.

- Education-based labour market profile of workers reflects a very low representation of both men and women in tertiary education, where the latter's position is even worse. The highest proportion of workers are those with secondary education, followed by those without any schooling as well as those with primary education. Over time, there has been an increase in all education groups, with a large reduction of the proportion of those 
without any schooling. In the case of paid employees, the proportion of workers with tertiary education is thought to be much higher: in the first part of our analysis, there has been a decline in this group of workers; however, this has reversed in the second part. Thus, it appears that over time there has been an overall increase in the educated workforce leading to a corresponding increase in high-skilled workers.

- In terms of the skill component of workers, mid-skilled workers make up almost half of the workforce, with a high proportion of low-skilled workers in the workforce as well. However, we observe a large fall in the proportion of the low-skilled workforce in the second period of our analysis, with an increase in the proportion of mid-skilled workers. As for paid employees, a similar trend can be found.

- For all education groups, we observe an increase in real earnings, with those having tertiary education experiencing the highest increment. As for paid employees, as expected, those without any schooling have experienced a fall in real earnings along with those in primary education. As for education premium, for those holding a degree in tertiary education, education premium has been highest and that too has increased consistently for both sexes. For those with secondary education, there has been an overall increase as well. In terms of skill level, the highest increase in real earnings has been experienced by those working in high-skilled occupation, especially managers and professionals.

- Our regression-based polarization tests reflect polarization in employment in the first period but not in the second period of our analysis; therefore, for the entire time period, we do not observe polarization in employment. However, our estimation result confirms earnings polarization with a U-shaped pattern between earnings and skill levels.

- Our regression analysis of changes in employment share reflects no statistically significant evidence of increase/decrease in RTI over the entire period, and for both O*NET RTI measure and country-specific RTI measure we get more or less similar findings. However, our descriptive suggests almost no change in average country RTI during the first period of our analysis but a fall in average country RTI in the second period. As for the earningsbased regression-specific RTI analysis, we find that, in case of occupations with higher routine-task content, there has been a negative change in earnings and the results have become significant when country RTI measure has been applied. Our analysis, therefore, reveals higher returns towards more skilled and less routine-intensive tasks.

- In case of analysis of earnings inequality, we have adopted several techniques and though not highly consistent and conclusive, the Gini index shows that there has been a fall in inequality over time, especially in the second period of our analysis, with inequality remaining almost stable in the first period.

- To understand the factors behind inequality in earnings, a number of decomposition techniques-mainly Shapley and RIF decompositions-have been applied. Shapley decomposition has shown that, in the context of Bangladesh, inequality can be mostly explained by within-occupation differences; however, the dominance of betweenoccupation differences has grown over time. According to RIF decomposition, it can be inferred that it is primarily the 'earning structure effect' rather than the 'characteristics effect' that has played the key role behind changes in inequality over time. Further analysis of earnings structure decomposition reflects that RTI along with education explains most of the differences in earnings for different earnings quantiles. In particular, for the first period RTI had a pro-rich effect and education had a pro-poor effect, whereas in the second period RTI had a pro-poor effect on inequality.

Summing up the results, we can deduce that, in terms of skill content of the workers, there has been a shift towards educated and better skilled workers with a gradual movement towards jobs with less routine-intensive tasks. We also observe that, although there has been increase in real labour earnings for all education and broad skill levels with increase in returns to education, this 
has not been translated into growing inequality as we have observed a decline in earnings inequality in recent years.

Against the backdrop of our analysis, we suggest a number of policies. First, given the high education premium, investing in education should be the highest priority. The need to reorient education programmes catering to the necessities of the labour market is even more pertinent in light of the results of our detailed RIF decomposition analysis, which indicates exhaustion of the pro-poor effect of education in later part of our analysis. Our analysis also reflects that the share of workers with tertiary education is quite low so despite those with tertiary education enjoying the highest earnings premium, we have not been able to reap the benefits of this premium.

Second, with declining importance of routine-intensive tasks, greater emphasis is needed on skillbiased training programmes, particularly those involving cognitive skill. With pro-poor effect of RTI in recent years, training related to jobs with less routine-intensive tasks will be equalityinducing as well.

Third, we should not be complacent with the falling trend of earnings inequality in the country, as our findings reveal this can be linked primarily to a number of factors apparently outside of the labour market. One such factor is the taxation system of the country that is far from progressive, with the tax-GDP ratio hovering at less than 10 per cent-one of the lowest in the world. It is also widely argued that a number of institutional weaknesses, especially those in the financial sector, have contributed towards raising the income of those at the upper end of the distribution. Our Shapley decomposition also suggests that inequality is mostly explained by institutional factors that are not directly related to mean earnings across occupations. The striking differences in the trend of income and consumption Gini also suggest interpreting inequality with caution. Therefore, earnings inequality should be explained and analysed while considering the broader picture of the economy. The low capacity of growth to generate employment as reflected in the employment elasticity of growth has constrained individuals to realize their potential in the labour market and thereby could have aggravated inequality in the economy.

Fourth, the role of structural change in transforming the occupational as well as earnings structure of the country is quite apparent. However, given the shift towards less routine-intensive tasks, lowskilled jobs, particularly those in agriculture, still constitute a significant part of the labour force. The fruits of structural transformation, therefore, have not quite benefited the labour market that necessitates, on the one hand, creation of jobs in the non-agriculture sector targeting the midskilled and, on the other hand, investment in upskilling the low-skilled.

Fifth, as Bangladesh continues its journey towards becoming a developed country backed by a structural shift towards less routine-intensive tasks and a skilled workforce, it would be pertinent to bring more sectors under coverage of the minimum wage law and to establish trade unions in order to ensure that benefits emanating from such a structural change are distributed evenly across all worker groups. At present, minimum wages have been set by the Minimum Wages Board for 42 industrial and commercial sub-sectors, including for the RMG sector. Employment in the RMG sector has expanded over the years, where implementation of minimum wage has been somewhat effective. However, with a significant percentage of workers engaged in informal employment and, therefore, not being protected by the minimum wage law, it has been largely ineffective in influencing earnings distribution.

Finally, we have found that despite a relatively moderate increase in earnings in mid-skilled jobs compared with high-skilled ones, employment in mid-skilled jobs has significantly increased. This indicates the presence of skill mismatch/skill gap that needs to be addressed through effective policy interventions. There is a need to align education policies with skills demanded in the labour 
market. Our findings of regression analysis with regard to job polarization also emphasize this mismatch, as earnings have increased for less routine-intensive tasks but this has not resulted in a proportional increase in the employment share of less routine-intensive tasks.

\section{References}

Acemoglu, D., and D. Autor (2011). 'Skills, Tasks and Technologies: Implications for Employment and Earnings'. In O. Ashenfelter and D. Card (eds), Handbook of Labor Economics (Vol. 4, pp. 1043-171). Amsterdam: Elsevier. https://doi.org/10.1016/S0169-7218(11)02410-5

Acemoglu, D., and P. Restrepo (2017). 'Robots and Jobs: Evidence from US Labor Markets. NBER Working Paper w23285. Cambridge, MA: National Bureau of Economic Research (NBER). https://doi.org/10.3386/w23285

Acemoglu, D., and P. Restrepo (2018). 'Artificial Intelligence, Automation and Work'. NBER Working Paper 24196. Cambridge, MA: National Bureau of Economic Research (NBER). https://doi.org/10.3386/w24196

ADB (2016). Bangladesh: Looking beyond Garments. Employment Diagnostic Study. Philippines: Asian Development Bank (ADB). Available at: https://www.adb.org/sites/default/ files/publication/190589/ban-beyond-garments-eds.pdf (accessed December 2020).

Autor, D.H., and D. Dorn (2009). 'Inequality and Specialization: The Growth of Low-Skill Service Jobs in the United States'. NBER Working Paper 15150. Cambridge, MA: National Bureau of Economic Research (NBER). Available at: https://www.nber.org/system/files/working_papers/w15150/revisions/w15150.rev0.pdf (accessed December 2020).

Autor, D., and D. Dorn (2013). 'The Growth of Low-Skill Service Jobs and the Polarization of the US Labor Market'. American Economic Review, 103(5): 1553-97. https:// doi.org/10.1257/aer.103.5.1553

Autor, D.H., D. Dorn, and G.H. Hanson (2015). 'Untangling Trade and Technology: Evidence from Local Labour Markets'. The Economic Journal, 125(584): 621-46. https://doi.org/10.1111/ecoj.12245

Autor, D.H., F. Levy, and R.J. Murnane (2003). 'The Skill Content of Recent Technological Change: An Empirical Exploration'. The Quarterly Joumal of Economics, 118(4): 1279-333. https://doi.org/10.1162/003355303322552801

Apella, I., and G. Zunino (2018). 'Nonstandard Forms of Employment in Developing Countries: A Study for a Set of Selected Countries in Latin America and the Caribbean and Europe and Central Asia'. Policy Research Working Paper 8581. Washington, DC: The World Bank. https://doi.org/10.1596/1813-9450-8581

Arias, O.S., C. Sánchez-Páramo, M.E. Dávalos, I. Santos, E.R. Tiongson, C. Gruen, N. de Andrade Falcão, G. Saiovici, and C.A. Cancho (2014). Back to Work: Growing with Jobs in Europe and Central Asia. Europe and Central Asia Reports. Washington, DC: The World Bank. https://doi.org/10.1596/978-0-82139910-1

BBS (2018). Labour Force Survey. Dhaka: Bangladesh Bureau of Statistics (BBS). Available at: https://www.ilo.org/surveyLib/index.php/catalog/2214 (accessed December 2020).

BBS (2019). Household Income and Expenditure Survey, 2016-2017. Dhaka: Bangladesh Bureau of Statistics (BBS). Available at: https://catalog.ihsn.org/index.php/catalog/7399 (accessed December 2020).

Berman, E., and S. Machin (2000). 'Skill-Biased Technology Transfer around the World'. Oxford Review of Economic Policy, 16(3): 12-22. https://doi.org/10.1093/oxrep/16.3.12 
Chantreuil, F., and A. Trannoy (1997). 'Inequality Decomposition Values'. Mimeo. France: Université de Cergy-Pointoise.

Du, Y., and A. Park (2018). 'Changing Demand for Tasks and Skills in China'. Background Report for the World Bank Group (WBG)-Development Research Center under the State Council (DRC) Report on New Drivers of Growth in China. Washington, DC: The World Bank. Available at: http://hdl.handle.net/10986/32351 (accessed December 2020).

Eden, M., and P. Gaggl (2020). 'Do Poor Countries Really Need More IT?'. The World Bank Economic Review, 34(1): 48-62. https://doi.org/10.1093/wber/lhy022

Export Promotion Bureau (2020). Export Promotion Bureau, Bangladesh. Available at: http://www.epb.gov.bd (accessed 20 August 2020).

Firpo, S., N.M. Fortin, and T. Lemieux (2009). 'Unconditional Quantile Regressions'. Econometrica, 77(3): 953-73. https://doi.org/10.3982/ECTA6822

Firpo, S., N.M. Fortin, and T. Lemieux, T. (2011). 'Occupational Tasks and Changes in the Wage Structure' IZA Discussion Paper 5542. Bonn: Institute of Labor Economics. Available at: http://ftp.iza.org/dp5542.pdf (accessed December 2020).

GED (2019). Study on Employment, Productivity and Sectoral Investment in Bangladesh. Project completed by the South Asian Network on Economic Modelling (SANEM). Dhaka: General Economics Division (GED), Ministry of Planning Commission, Government of the People's Republic of Bangladesh.

Goos, M., and A. Manning (2007). 'Lousy and Lovely Jobs: The Rising Polarization of Work in Britain'. The Review of Economics and Statistics, 89(1): 118-33. https://doi.org/10.1162/rest.89.1.118

Goos, M., A. Manning, and A. Salomons (2014). 'Explaining Job Polarization: Routine-Biased Technological Change and Offshoring. American Economic Review, 104(8): 2509-26. https://doi.org/10.1257/aer.104.8.2509

Gradín, C., and S. Schotte (2020). 'Implications of the Changing Nature of Work for Employment and Inequality in Ghana'. WIDER Working Paper 2020/119. Helsinki: UNU-WIDER. https://doi.org/10.35188/UNU-WIDER/2020/876-4

Grossman, G.M., and E. Rossi-Hansberg (2008). 'Trading Tasks: A Simple Theory of Offshoring'. American Economic Review, 98(5): 1978-97. https://doi.org/10.1257/aer.98.5.1978

Hardy, W., R. Keister, and P. Lewandowski (2018). 'Educational Upgrading, Structural Change and the Task Composition of Jobs in Europe'. Economics of Transition and Institutional Change, 26(2): 201-31. https://doi.org/10.1111/ecot.12145

Hardy, W., P. Lewandowski, A. Park, and D. Yang (2018). 'The Global Distribution of Routine and NonRoutine Work: Findings from PIAAC, STEP and CULS'. IBS Working Paper 05/2018. Warsaw: Institute for Structural Research (IBS). Available at: http://conference.iza.org/conference_files/WoLabConf_2018/lewandowski_p9882.pdf (accessed December 2020).

Hsieh, C.T., and P.J. Klenow (2010). 'Development Accounting'. American Economic Journal: Macroeconomics, 2(1): 207-23. https://doi.org/10.1257/mac.2.1.207

Khan, A.R., and B. Sen (2001). 'Inequality and Its Sources in Bangladesh, 1991/92 to 1995/96: An Analysis based on Household Expenditure Surveys. The Bangladesh Development Studies, 27(1): 1-49. Available at: https://www.jstor.org/stable/40795620 (accessed December 2020).

Kuriakose, F., and D.K. Iyer (2020). 'Job Polarisation in India: Structural Causes and Policy Implications'. The Indian Journal of Labour Economics, 63(2): 247-66. https:/ / doi.org/10.1007/s41027-020-00216-7

Lewandowski, P. (2017). 'The Changing Nature of Jobs in Central and Eastern Europe'. IZA World of Labor. https://doi.org/10.15185/izawol.351

Lewandowski, P., A. Park, W. Hardy, and Y. Du (2019). `Technology, Skills, and Globalization: Explaining International Differences in Routine and Non-Routine Work Using Survey Data'. HKUST IEMS 
Working Paper 2019-60. Hong Kong: Hong Kong University of Science \& Technology (HKUST) and Institute for Emerging Market Studies (IEMS). https://doi.org/10.2139/ssrn.3415008

Lewandowski, P., A. Park, and S. Schotte (2020). 'The Global Distribution of Routine and Non-Routine Work'. WIDER Working Paper 2020/75. Helsinki: UNU-WIDER. https:// doi.org/10.35188/UNUWIDER/2020/832-0

Lo Bello, S., M.L. Sanchez Puerta, and H.J. Winkler (2019). 'From Ghana to America: The Skill Content of Jobs and Economic Development'. Policy Research Working Paper 8758. Washington, DC: World Bank. https://doi.org/10.1596/1813-9450-8758

Ministry of Finance (2019). Bangladesh Economic Review (Chapter 3). Dhaka: Finance Division, Ministry of Finance, Government of the People's Republic of Bangladesh. Available at: https://mof.gov.bd/site/page/44e399b3-d378-41aa-86ff-8c4277eb0990/Bangladesh-EconomicReview (accessed December 2020).

Osmani, S.R. (2015a). 'Linking Equity and Growth in Bangladesh'. Background paper prepared for the Seventh Five Year Plan of the Government of Bangladesh. Dhaka: Bangladesh Planning Commission, Government of the People's Republic of Bangladesh.

Osmani, S.R. (2015b). The Growth-Equity Nexus in Bangladesh: An Analysis of Recent Experience. Bangladesh Development Studies, 38(2): 1-59. Available at: https://pure.ulster.ac.uk/ws/portalfiles/portal/11545786/GrowthEquity+Nexus+in+Bangladesh.pdf (accessed December 2020).

Osmani, S.R. (2017). 'Eradicating Poverty and Minimizing Inequality for Ensuring Shared Prosperity in Bangladesh'. A background paper prepared for the Perspective Plan, 2021-2041. Dhaka: General Economics Division, Planning Commission, Government of the People's Republic of Bangladesh.

Osmani, S.R. (2018). 'Aspects of the Poverty Scenario in Bangladesh during 2010-2016'. Bangladesh Development Studies, 41(3): 1-31.

Osmani, S.R., and B. Sen (2011). 'Inequality in Rural Bangladesh in the 2000s: Trends and Causes'. The Bangladesh Development Studies, 34(4): 1-36. Available at: https://www.jstor.org/stable/23342752 (accessed December 2020).

Patrinos, A.H., and G. Psacharopoulos (2002). Returns to Investment in Education: A Further Update. Washington, DC: The World Bank. https://doi.org/10.1596/1813-9450-2881

Patrinos, H.A., and G. Psacharopoulos (2011). Education: Past, Present and Future Global Challenges. Washington, DC: The World Bank. https://doi.org/10.1596/1813-9450-5616

Patrinos, H.A., and G. Psacharopoulos (2020). 'Returns to Education in Developing Countries'. In S. Bradley and C. Green (eds), The Economics of Education (pp. 53-64). Amsterdam: Academic Press/Elsevier. https:// doi.org/10.1016/B978-0-12-815391-8.00004-5.

Psacharopoulos, G. (1972). 'Rates of Return to Investment in Education around the World'. Comparative Education Review, 16(1): 54-67. https:/ / doi.org/10.1086/445569

Psacharopoulos, G. (1981). 'Returns to Education: An Updated International Comparison'. Comparative Education, 17(3): 321-41. https:/ / doi.org/10.1080/0305006810170308

Psacharopoulos, G. (1985). 'Returns to Education: A Further International Update and Implications. Journal of Human Resources, 20(4): 583-604. https://www.jstor.org/stable/145686

Psacharopoulos, G. (1993). 'Returns to Investment in Education: A Global Update'. Policy Research Working Paper 1067. Washington, DC: The World Bank. Available at: http:// documents1.worldbank.org/curated/en/468021468764713892/pdf/multi-page.pdf (accessed December 2020).

Psacharopoulos, G. (1994). 'Returns to Investment in Education: A Global Update'. World Development, 22(9): 1325-43. https://doi.org/10.1016/0305-750X(94)90007-8 
Psacharopoulos, G. (2006). 'The Value of Investment in Education: Theory, Evidence, and Policy'. Journal of Education Finance, 32(2): 113-36. Available at: http://www.jstor.org/stable/40704288 (accessed December 2020).

Psacharopoulos, G., and H.A. Patrinos (2018). Returns to Investment in Education: a Decennial Review of the Global Literature. Washington, DC: The World Bank. https://doi.org/10.1596/1813-9450-8402

Raihan, S., and S.H. Bidisha (2018). 'Female Employment Stagnation in Bangladesh'. EDIG Research Paper Five. Dhaka: Economic Dialogue on Inclusive Growth (EDIG) in Bangladesh. Available at: https://asiafoundation.org/wp-content/uploads/2018/12/EDIG-Female-employment-stagnationin-Bangladesh_report.pdf (accessed December 2020).

Raihan, S., and S.S. Khan (2020). 'Structural Transformation, Inequality Dynamics, and Inclusive Growth in Bangladesh' WIDER Working Paper 2020/44. Helsinki: UNU-WIDER. https://doi.org/10.35188/UNU-WIDER/2020/801-6

Sebastian, R. (2018). 'Explaining Job Polarisation in Spain from a Task Perspective'. SERIEs, 9(2): 215-48. https://doi.org/10.1007/s13209-018-0177-1

Shorrocks, A.F. (2013). 'Decomposition Procedures for Distributional Analysis: A Unified Framework Based on the Shapley Value'. The Journal of Economic Inequality, 11(1): 99-126. https://doi.org/10.1007/s10888-011-9214-z

Vashisht, P., and J.D. Dubey (2018). 'Changing Task Contents of Jobs in India: Implications and Way Forward'. ICRIER Working Paper 355. New Delhi: Indian Council for Research on International Economic Relations (ICRIER). Available at: https://icrier.org/pdf/Working_Paper_355.pdf (accessed December 2020). 


\section{Appendix}

\section{Tables}

Table A1: Gini index

\begin{tabular}{lcccccc}
\hline Year & \multicolumn{3}{c}{ Income Gini } & \multicolumn{3}{c}{ Consumption Gini } \\
\cline { 2 - 7 } & National & Rural & Urban & National & Rural & Urban \\
\hline $1991 / 92$ & 0.388 & 0.364 & 0.398 & 0.259 & 0.243 & 0.307 \\
$1995 / 96$ & 0.432 & 0.384 & 0.444 & 0.302 & 0.265 & 0.363 \\
2000 & 0.451 & 0.393 & 0.497 & 0.307 & 0.271 & 0.368 \\
2005 & 0.467 & 0.428 & 0.497 & 0.310 & 0.278 & 0.353 \\
2010 & 0.458 & 0.431 & 0.452 & 0.320 & 0.275 & 0.338 \\
2016 & 0.483 & 0.454 & 0.498 & 0.324 & 0.300 & 0.330 \\
\hline
\end{tabular}

Source: authors' calculation based on BBS (2019).

Table A2: Employment elasticity of growth

\begin{tabular}{lcccc}
\hline Sector & $1995 / 96-1999 / 2000$ & $1999 / 2000-2005 / 06$ & $2005 / 06-2009 / 10$ & $2009 / 10-2017 / 18$ \\
\hline Agriculture & 0.73 & 0.82 & 0.71 & -0.09 \\
Manufacturing & 0.26 & 0.78 & 0.87 & 0.65 \\
Construction & 0.27 & 0.63 & 2.22 & 0.55 \\
Services & 0.21 & 0.69 & 0.27 & 0.40 \\
GDP & 0.54 & 0.59 & 0.55 & 0.25 \\
\hline
\end{tabular}

Source: authors' calculation based on GED (2019; sample households survey by SANEM for the General Economics Division, Ministry of Planning Commission) and ADB (2016).

Table A3: Trend of labour force participation rate (\%)

\begin{tabular}{lcccccc}
\hline & $1999 / 2000$ & $2005 / 06$ & 2010 & 2013 & $2015 / 16$ & $2016 / 17$ \\
\hline All & 54.9 & 58.5 & 59.3 & 57.1 & 58.5 & 58.2 \\
Male & 84.2 & 86.8 & 82.5 & 81.7 & 81.9 & 80.5 \\
Female & 23.9 & 29.2 & 36 & 33.5 & 35.6 & 36.3 \\
\hline
\end{tabular}

Source: authors' calculation based on Labour Force Survey (LFS, different years) and Raihan and Bidisha (2018).

Table A4: Trend of labour force participation rate (\%)-Type of employment

\begin{tabular}{lcccccc}
\hline \multirow{2}{*}{ Types } & \multicolumn{2}{c}{2005} & \multicolumn{2}{c}{2010} & \multicolumn{2}{c}{$2016 / 17$} \\
\cline { 2 - 7 } & Male & Female & Male & Female & Male & Female \\
\hline Wage employment & 40.0 & 23.9 & 46.1 & 18.5 & 42.6 & 31.2 \\
Self-employment & 50.4 & 16.0 & 47.7 & 25.3 & 52.5 & 39.2 \\
Unpaid family worker & 9.7 & 60.1 & 7.1 & 56.3 & 4.2 & 29.1 \\
\hline
\end{tabular}

Source: authors' calculation based on LFSs (different years) and Raihan and Bidisha (2018).

Table A5: Trend of sector-wise labour force participation (\%)

\begin{tabular}{ccccccc}
\hline & $1999 / 2000$ & $2005 / 06$ & 2010 & 2013 & $2015 / 16$ & $2016 / 17$ \\
\hline Agriculture & 51.3 & 48 & 47.5 & 45.1 & 42.7 & 40.6 \\
Male & 52.2 & 41.8 & 40.1 & 41.7 & 34 & 32.2 \\
Female & 47.6 & 68.1 & 64.8 & 53.5 & 63.1 & 59.7 \\
Industry & 13.1 & 14.5 & 17.7 & 20.8 & 20.5 & 20.4 \\
Male & 11.3 & 15.1 & 19.6 & 19.6 & 22.3 & 22 \\
Female & 20 & 12.5 & 13.3 & 23.7 & 16.1 & 16.8 \\
\hline
\end{tabular}




\begin{tabular}{lcccccc}
\hline Manufacturing & 9.5 & 11 & 12.4 & 16.4 & 14.4 & 14.4 \\
Male & 7.4 & 10.8 & 12.7 & 13.9 & 14.2 & 14 \\
Female & 17.9 & 11.5 & 11.7 & 22.5 & 14.9 & 15.4 \\
Service & 35.6 & 37.4 & 35.3 & 34.1 & 36.9 & 39 \\
Male & 36.4 & 43 & 41.1 & 38.7 & 43.7 & 45.8 \\
Female & 32.2 & 19.3 & 21.8 & 22.8 & 20.8 & 23.5 \\
\hline
\end{tabular}

Source: authors' calculation based on LFS (different years) and Raihan and Bidisha (2018).

Table A6: Distribution of workers by gender and level of education (paid employees only) (\%)

\begin{tabular}{lccccccccc}
\hline Highest level of education & \multicolumn{4}{c}{ Male } & \multicolumn{3}{c}{ Female } & \multicolumn{3}{c}{ Total } \\
\cline { 2 - 11 } & 2005 & 2010 & $2016 / 17$ & 2005 & 2010 & $2016 / 17$ & 2005 & 2010 & $2016 / 17$ \\
\hline No schooling & 9.3 & 12.5 & 8.21 & 20.99 & 21.21 & 20.05 & 11.68 & 14.11 & 11.83 \\
Primary & 16.12 & 14.91 & 19.08 & 21.54 & 21.33 & 23.6 & 17.22 & 16.1 & 20.47 \\
Secondary & 50.05 & 54.33 & 50.39 & 36.96 & 43.31 & 41.8 & 47.4 & 52.3 & 47.76 \\
Tertiary & 24.52 & 18.26 & 22.32 & 20.5 & 14.15 & 14.55 & 23.71 & 17.5 & 19.94
\end{tabular}

Source: authors' calculation using various rounds (2005, 2010, 2016/17) of LFS.

Table A7: Distribution of workers by gender and occupation (\%)

\begin{tabular}{lccccccccc}
\hline ISCO-88 (one-digit) & \multicolumn{3}{c}{ Male } & \multicolumn{3}{c}{ Female } & \multicolumn{3}{c}{ Total } \\
\cline { 2 - 10 } & 2005 & 2010 & $2016 / 17$ & 2005 & 2010 & $2016 / 17$ & 2005 & 2010 & $2016 / 17$ \\
\hline 1 Managers & 0.58 & 1.49 & 2.23 & 0.2 & 0.58 & 0.82 & 0.49 & 1.21 & 1.9 \\
2 Professionals & 3.28 & 3.22 & 2.48 & 3.2 & 2.14 & 2.83 & 3.26 & 2.89 & 2.56 \\
$\begin{array}{l}\text { 3 Technicians and associate } \\
\text { professionals }\end{array}$ & 1.62 & 1.85 & 3.76 & 1.45 & 1.05 & 6.72 & 1.58 & 1.6 & 4.46 \\
4 Clerical support workers & 2.47 & 2.47 & 1.99 & 1.36 & 0.64 & 1.14 & 2.21 & 1.9 & 1.79 \\
$\begin{array}{l}\text { 5 Services and sales workers } \\
\text { 6 Skilled agricultural, forestry }\end{array}$ & 23.13 & 21.07 & 20.47 & 6.29 & 10.11 & 6.51 & 19.2 & 17.7 & 17.18 \\
$\begin{array}{l}\text { and fishery workers } \\
\text { 7 Craft and related trade }\end{array}$ & 9.5 & 16.31 & 19.85 & 63.18 & 64.92 & 35.97 & 32.25 & 31.25 & 23.64 \\
workers & 9.82 & 17.72 & 8.26 & 7.8 & 25.67 & 9.21 & 9.2 & 19.59 \\
$\begin{array}{l}\text { 8 Plant and machine } \\
\text { operators and assemblers }\end{array}$ & 5.78 & 6.49 & 10.61 & 3.84 & 4.78 & 3.46 & 5.33 & 5.97 & 8.93 \\
9 Elementary occupations & 30.82 & 37.28 & 20.9 & 12.2 & 7.99 & 16.88 & 26.47 & 28.28 & 19.95 \\
\hline
\end{tabular}

Source: authors' calculation using various rounds $(2005,2010,2016 / 17)$ of LFS.

Table A8: Distribution of workers by gender and occupation (paid employees only) (\%)

\begin{tabular}{|c|c|c|c|c|c|c|c|c|c|}
\hline \multirow[t]{2}{*}{ ISCO-88 (one-digit) } & \multicolumn{3}{|c|}{ Male } & \multicolumn{3}{|c|}{ Female } & \multicolumn{3}{|c|}{ Total } \\
\hline & 2005 & 2010 & $2016 / 17$ & 2005 & 2010 & $2016 / 17$ & 2005 & 2010 & $2016 / 17$ \\
\hline 1 Managers & 0.87 & 2.7 & 8.02 & 0.31 & 1.01 & 2.16 & 0.76 & 2.39 & 6.22 \\
\hline 2 Professionals & 17.58 & 14.46 & 8.95 & 22.74 & 18.75 & 7.64 & 18.63 & 15.25 & 8.55 \\
\hline $\begin{array}{l}3 \text { Technicians and associate } \\
\text { professionals }\end{array}$ & 7.98 & 6.26 & 10.28 & 9.57 & 6.91 & 15.89 & 8.3 & 6.38 & 12 \\
\hline 4 Clerical support workers & 12.53 & 8.85 & 7.34 & 9.36 & 4.53 & 3.18 & 11.89 & 8.05 & 6.07 \\
\hline 5 Services and sales workers & 21.95 & 16.55 & 14.92 & 7.08 & 3.03 & 7.77 & 18.93 & 14.05 & 12.73 \\
\hline $\begin{array}{l}6 \text { Skilled agricultural, forestry } \\
\text { and fishery workers }\end{array}$ & 0.71 & 0.59 & 0.7 & 0.13 & 5.36 & 0.7 & 0.6 & 1.47 & 0.7 \\
\hline $\begin{array}{l}7 \text { Craft and related trade } \\
\text { workers }\end{array}$ & 10.11 & 9.78 & 24.72 & 9.03 & 10.55 & 39.17 & 9.89 & 9.92 & 29.14 \\
\hline $\begin{array}{l}8 \text { Plant and machine } \\
\text { operators and assemblers }\end{array}$ & 13.7 & 20.1 & 15.16 & 26.52 & 38.88 & 7.25 & 16.3 & 23.57 & 12.74 \\
\hline 9 Elementary occupations & 14.57 & 20.72 & 9.9 & 15.26 & 10.98 & 16.25 & 14.71 & 18.92 & 11.84 \\
\hline
\end{tabular}

Source: authors' calculation using various rounds (2005, 2010, 2016/17) of LFS. 
Table A9: Distribution of workers by gender and occupation (paid employees only) (\%)

\begin{tabular}{lccccccccc}
\hline Skill level & \multicolumn{3}{c}{ Male } & \multicolumn{3}{c}{ Female } & \multicolumn{3}{c}{ Total } \\
\cline { 2 - 9 } & 2005 & 2010 & $2016 / 17$ & 2005 & 2010 & $2016 / 17$ & 2005 & 2010 & $2016 / 17$ \\
\hline High & 26.44 & 23.42 & 27.26 & 32.62 & 26.67 & 25.69 & 27.69 & 24.02 & 26.78 \\
Medium & 58.28 & 55.28 & 62.14 & 51.99 & 56.99 & 57.37 & 57 & 55.59 & 60.68 \\
Low & 15.28 & 21.31 & 10.6 & 15.39 & 16.34 & 16.94 & 15.31 & 20.39 & 12.54 \\
\hline
\end{tabular}

Source: authors' calculation using various rounds (2005, 2010, 2016/17) of LFS.

Table A10: Real mean earnings by gender and level of education (paid employees) (in BDT)

\begin{tabular}{lccccccccc}
\hline Highest class passed & \multicolumn{3}{c}{ Male } & \multicolumn{3}{c}{ Female } & \multicolumn{3}{c}{ Total } \\
\cline { 2 - 10 } & 2005 & 2010 & $2016 / 17$ & 2005 & 2010 & $2016 / 17$ & 2005 & 2010 & $2016 / 17$ \\
\hline No schooling & 1,790 & 1,883 & 1,602 & 1,367 & 1,499 & 1,339 & 1,637 & 1,776 & 1,466 \\
Primary & 1,800 & 1,691 & 1,647 & 1,498 & 1,464 & 1,538 & 1,722 & 1,635 & 1,608 \\
Secondary & 1,991 & 2,051 & 2,212 & 1,840 & 1,720 & 2,030 & 1,967 & 2,001 & 2,163 \\
Tertiary & 2,383 & 3,668 & 4,503 & 2,394 & 2,545 & 3,882 & 2,385 & 3,500 & 4,365 \\
Total & 2,037 & 2,272 & 2,566 & 1,781 & 1,735 & 2,047 & 1,985 & 2,173 & 2,407 \\
\hline
\end{tabular}

Note: BDT, Bangladeshi taka.

Source: authors' calculation using various rounds (2005, 2010, 2016/17) of LFS.

Table A11: Real mean weekly earnings by gender and occupation (in BDT)

\begin{tabular}{|c|c|c|c|c|c|c|c|c|c|}
\hline \multirow[t]{2}{*}{ ISCO-88 (one-digit) } & \multicolumn{3}{|c|}{ Male } & \multicolumn{3}{|c|}{ Female } & \multicolumn{3}{|c|}{ Total } \\
\hline & 2005 & 2010 & $2016 / 17$ & 2005 & 2010 & $2016 / 17$ & 2005 & 2010 & $2016 / 17$ \\
\hline 1 Managers & 3,126 & 3,647 & 5,204 & 2,223 & 2,402 & 4,918 & 3,093 & 3,562 & 5,173 \\
\hline 2 Professionals & 2,469 & 2,682 & 3,997 & 2,375 & 2,044 & 3,735 & 2,445 & 2,536 & 3,925 \\
\hline $\begin{array}{l}3 \text { Technicians and associate } \\
\text { professionals }\end{array}$ & 2,165 & 2,578 & 3,209 & 2,015 & 2,034 & 2,996 & 2,129 & 2,489 & 3,124 \\
\hline 4 Clerical support workers & 2,115 & 2,549 & 2,588 & 1,922 & 2,258 & 2,292 & 2,085 & 2,522 & 2,541 \\
\hline 5 Services and sales workers & 1,809 & 1,972 & 1,876 & 1,147 & 1,655 & 1,689 & 1,707 & 1,947 & 1,844 \\
\hline $\begin{array}{l}6 \text { Skilled agricultural, forestry } \\
\text { and fishery workers }\end{array}$ & 971 & 1,598 & 1,304 & 823 & 1,167 & 1,352 & 966 & 1,486 & 1,309 \\
\hline $\begin{array}{l}7 \text { Craft and related trade } \\
\text { workers }\end{array}$ & 1,414 & 1,391 & 1,686 & 1,003 & 1,592 & 1,566 & 1,356 & 1,422 & 1,652 \\
\hline $\begin{array}{l}8 \text { Plant and machine } \\
\text { operators and assemblers }\end{array}$ & 1,468 & 1,716 & 1,994 & 1,274 & 1,243 & 1,860 & 1,418 & 1,604 & 1,975 \\
\hline 9 Elementary occupations & 901 & 1,205 & 1,326 & 823 & 1,254 & 1,135 & 892 & 1,208 & 1,282 \\
\hline Total & 1,342 & 1,611 & 1,981 & 1,276 & 1,468 & 1,821 & 1,332 & 1,594 & 1,943 \\
\hline
\end{tabular}

Source: authors' calculation using various rounds $(2005,2010,2016 / 17)$ of LFS.

Table A12: Real mean weekly earnings by gender and occupation (paid employees) (in BDT)

\begin{tabular}{lccccccccc}
\hline ISCO-88 (one-digit) & \multicolumn{3}{c}{ Male } & \multicolumn{4}{c}{ Female } & \multicolumn{3}{c}{ Total } \\
\cline { 2 - 10 } & 2005 & 2010 & $2016 / 17$ & 2005 & 2010 & $2016 / 17$ & 2005 & 2010 & $2016 / 17$ \\
\hline 1 Managers & 3,138 & 4,804 & 5,261 & 2,875 & 3,228 & 4,998 & 3,129 & 4,681 & 5,233 \\
2 Professionals & 2,476 & 2,795 & 4,029 & 2,385 & 2,156 & 3,764 & 2,453 & 2,650 & 3,956 \\
$\begin{array}{l}\text { 3 Technicians and associate } \\
\text { professionals }\end{array}$ & 2,176 & 2,642 & 3,284 & 2,054 & 2,097 & 3,015 & 2,148 & 2,533 & 3,175 \\
$\begin{array}{l}\text { 4 Clerical support workers } \\
\text { 5 Services and sales workers }\end{array}$ & 2,133 & 2,805 & 2,623 & 1,996 & 2,375 & 2,302 & 2,111 & 2,760 & 2,572 \\
$\begin{array}{l}\text { 6 Skilled agricultural, forestry } \\
\text { and fishery workers }\end{array}$ & 1,928 & 2,208 & 1,982 & 1,623 & 1,800 & 1,728 & 2,099 & 2,192 & 1,935 \\
$\begin{array}{l}\text { 7 Craft and related trade } \\
\text { workers }\end{array}$ & 2,073 & 1,753 & 1,845 & 1,941 & 2,102 & 1,601 & 2,049 & 1,822 & 1,744 \\
\hline
\end{tabular}




\begin{tabular}{|c|c|c|c|c|c|c|c|c|c|}
\hline $\begin{array}{l}8 \text { Plant and machine operators } \\
\text { and assemblers }\end{array}$ & 1,535 & 1,847 & 2,133 & 1,294 & 1,285 & 1,875 & 1,455 & 1,676 & 2,089 \\
\hline 9 Elementary occupations & 1,612 & 1,949 & 1,676 & 1,403 & 1,339 & 1,161 & 1,568 & 1,883 & 1,461 \\
\hline Total & 2,037 & 2,272 & 2,566 & 1,781 & 1,735 & 2,047 & 1,985 & 2,173 & 2,407 \\
\hline
\end{tabular}

Source: authors' calculation using various rounds (2005, 2010, 2016/17) of LFS.

Table A13: Real median weekly earnings (paid employees only)

\begin{tabular}{|c|c|c|c|c|c|c|c|c|c|c|c|c|}
\hline \multirow[t]{2}{*}{ Deciles } & \multicolumn{4}{|c|}{2005} & \multicolumn{4}{|c|}{2010} & \multicolumn{4}{|c|}{$2016 / 17$} \\
\hline & \multirow{2}{*}{$\begin{array}{c}\text { Coefficient } \\
0.036\end{array}$} & \multirow{2}{*}{$\begin{array}{c}\text { SE } \\
0.001\end{array}$} & \multicolumn{2}{|c|}{$95 \% \mathrm{Cl}$} & \multirow{2}{*}{$\begin{array}{c}\text { Coefficient } \\
0.026\end{array}$} & \multirow{2}{*}{$\begin{array}{c}\text { SE } \\
0.000\end{array}$} & \multicolumn{2}{|c|}{$95 \% \mathrm{Cl}$} & \multirow{2}{*}{$\begin{array}{c}\text { Coefficient } \\
0.036\end{array}$} & \multirow{2}{*}{$\begin{array}{c}\text { SE } \\
0.000\end{array}$} & \multicolumn{2}{|c|}{$95 \% \mathrm{Cl}$} \\
\hline $0-10$ & & & 0.035 & 0.037 & & & 0.025 & 0.027 & & & 0.035 & 0.036 \\
\hline 10-20 & 0.054 & 0.000 & 0.053 & 0.055 & 0.040 & 0.001 & 0.039 & 0.041 & 0.050 & 0.000 & 0.049 & 0.050 \\
\hline 20-30 & 0.064 & 0.001 & 0.062 & 0.066 & 0.051 & 0.001 & 0.050 & 0.052 & 0.056 & 0.000 & 0.055 & 0.056 \\
\hline $30-40$ & 0.073 & 0.000 & 0.072 & 0.074 & 0.000 & 0.001 & 0.064 & 0.067 & 0.005 & 0.000 & 0.064 & 0.065 \\
\hline $40-50$ & 0.085 & 0.001 & 0.083 & 0.086 & 0.079 & 0.001 & 0.077 & 0.081 & 0.071 & 0.000 & 0.070 & 0.072 \\
\hline 50-60 & 0.095 & 0.001 & 0.094 & 0.096 & 0.093 & 0.001 & 0.091 & 0.094 & 0.085 & 0.000 & 0.084 & 0.086 \\
\hline $60-70$ & 0.109 & 0.001 & 0.108 & 0.110 & 0.110 & 0.001 & 0.108 & 0.112 & 0.102 & 0.000 & 0.102 & 0.103 \\
\hline $70-80$ & 0.124 & 0.001 & 0.122 & 0.126 & 0.126 & 0.001 & 0.123 & 0.128 & 0.116 & 0.000 & 0.115 & 0.117 \\
\hline 80-90 & 0.146 & 0.001 & 0.144 & 0.147 & 0.135 & 0.001 & 0.132 & 0.137 & 0.143 & 0.001 & 0.142 & 0.145 \\
\hline 90-100 & 0.215 & 0.003 & 0.210 & 0.220 & 0.275 & 0.006 & 0.264 & 0.287 & 0.276 & 0.003 & 0.271 & 0.281 \\
\hline
\end{tabular}

Note: SE, standard error; $\mathrm{Cl}$, confidence interval.

Source: authors' calculation using various rounds $(2005,2010,2016 / 17)$ of LFS.

Table A14: Shapley decomposition

\begin{tabular}{lccccccccc}
\hline Gini & \multicolumn{3}{c}{ Actual } & \multicolumn{3}{c}{ Shares constant } & \multicolumn{3}{c}{ Means constant } \\
\cline { 2 - 10 } & 2005 & 2010 & $2016 / 17$ & 2005 & 2010 & $2016 / 17$ & 2005 & 2010 & $2016 / 17$ \\
\hline 1 Overall & 0.3677 & 0.3698 & 0.3198 & 0.3677 & 0.3609 & 0.3194 & 0.3677 & 0.3915 & 0.3019 \\
Shapley decomposition & & & & & & & & & \\
2 Between & 0.1563 & 0.1019 & 0.1718 & 0.1563 & 0.1165 & 0.1751 & 0.1563 & 0.1387 & 0.1522 \\
\% 2/1 & 43 & 28 & 54 & 43 & 32 & 55 & 43 & 35 & 50 \\
3 Within & 0.2115 & 0.2678 & 0.148 & 0.2115 & 0.2444 & 0.1443 & 0.2115 & 0.2528 & 0.1497 \\
\% 3/1 & 58 & 72 & 46 & 58 & 68 & 45 & 58 & 65 & 50 \\
\hline
\end{tabular}

Source: authors' calculation using various rounds (2005, 2010, 2016/17) of LFS.

Table A15: Change in the Gini index decomposed into the contribution of changes in employment shares and in mean earnings (Shapley decomposition based on Table 12), 2005-16/17

\begin{tabular}{lccc}
\hline & $2005-10$ & $2010-16 / 17$ & $2005-16 / 17$ \\
\hline Change in employment shares (mean earnings constant) & -0.016 & 0.024 & 0.007 \\
Change in mean earnings (employment shares constant) & -0.038 & 0.046 & 0.008 \\
Total change & -0.054 & 0.070 & 0.016 \\
\hline
\end{tabular}

Source: authors' calculation using various rounds (2005, 2010, 2016/17) of LFS. 


\section{Figures}

Figure A1: Trend of real GDP growth rate

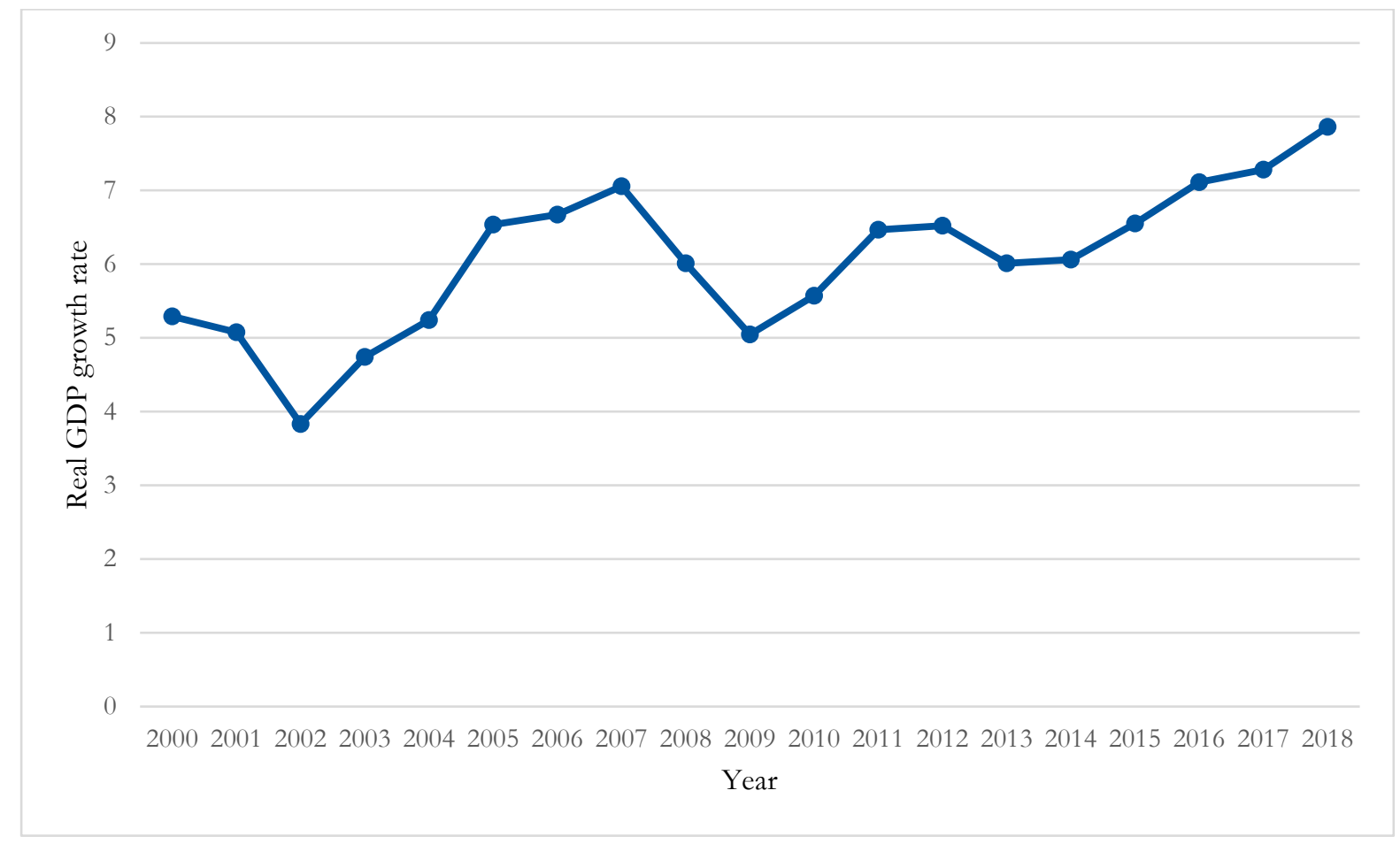

Source: authors' calculation based on World Development Indicators.

Figure A2: Skill- and education-wise change in employment share (all workers)

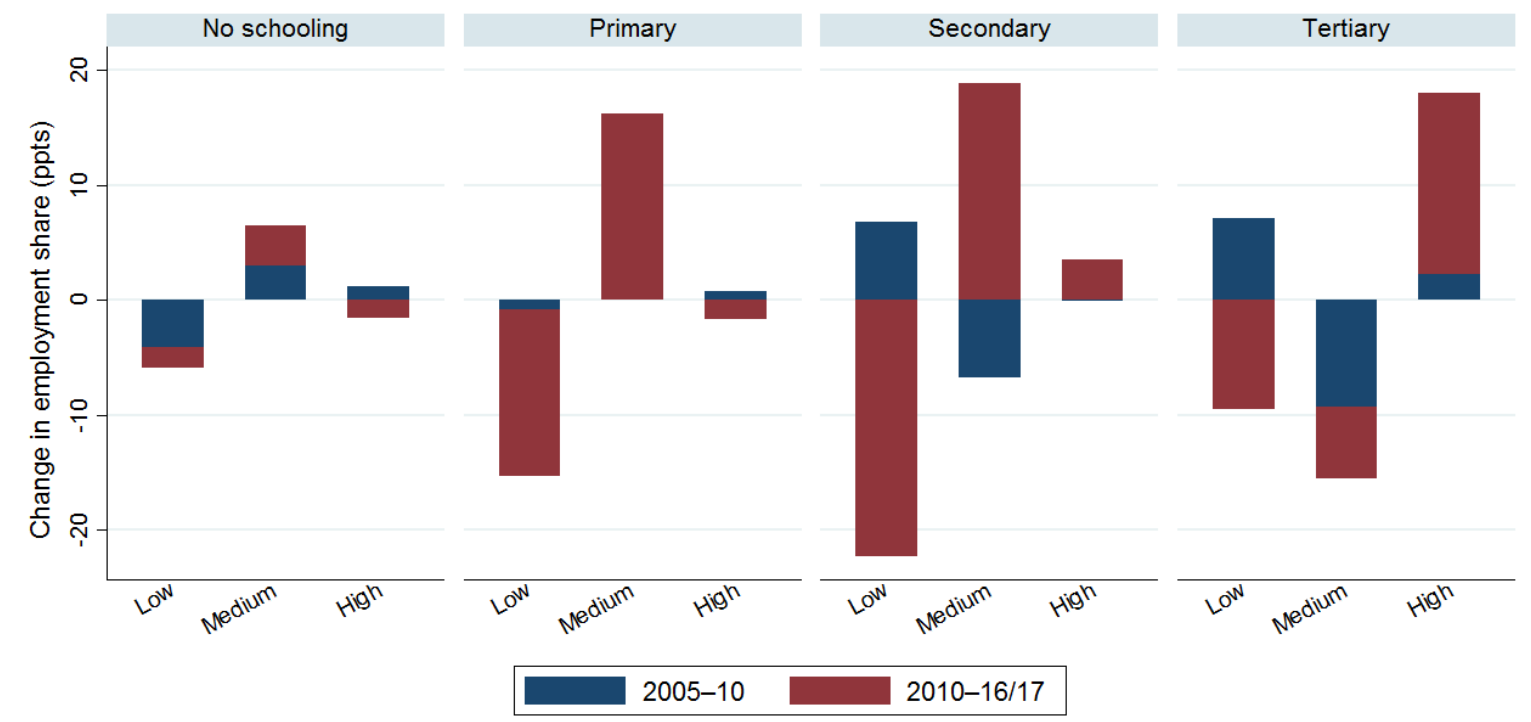

Source: authors' calculation using various rounds (2005, 2010, 2016/17) of Labour Force Survey (LFS). 
Figure A3: Changes in employment share (two-digit ISCO): (a) all workers; (b) paid workers

(a)

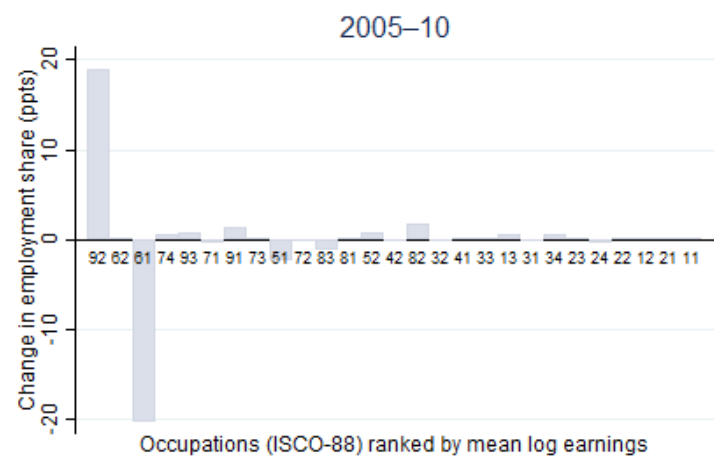

2010-16/17

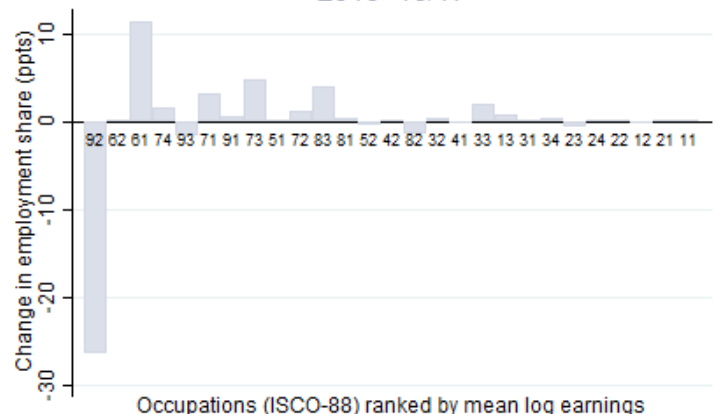

2005-16/17

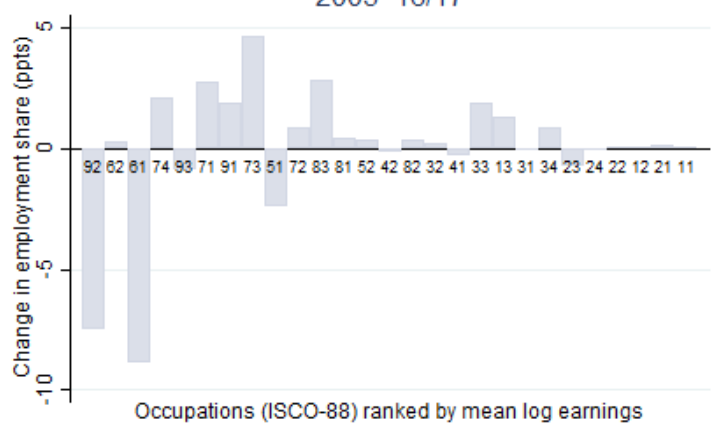

(b)

2005-10

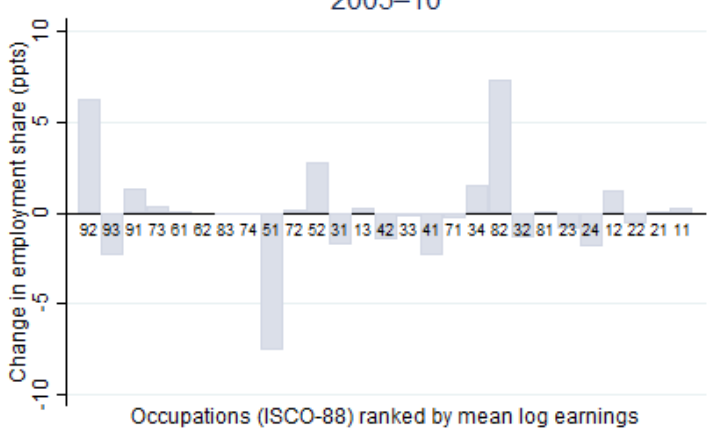

2010-16/17

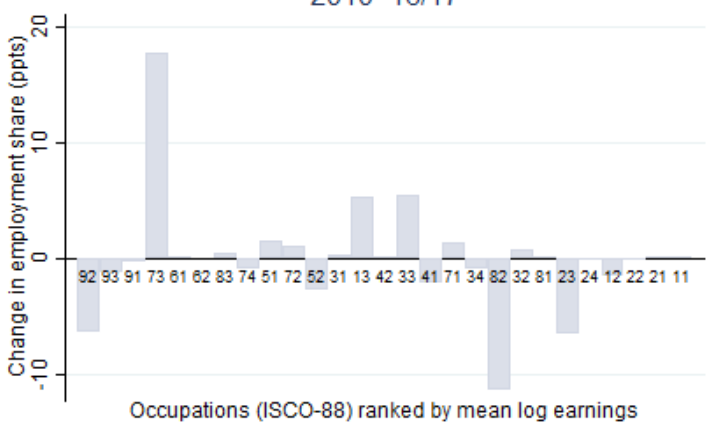

2005-16/17

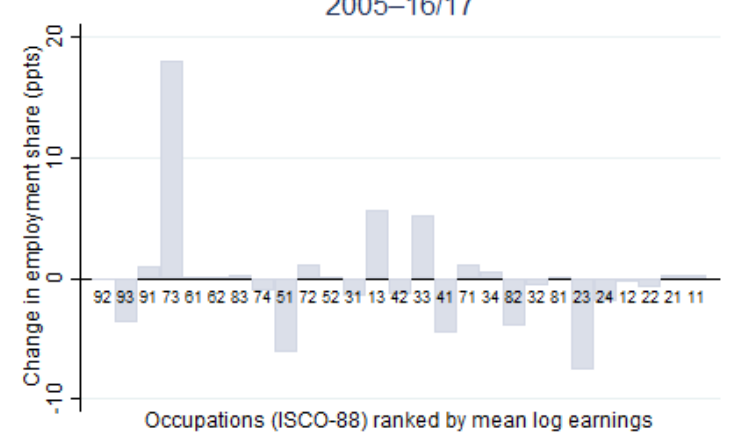

Source: authors' calculation using various rounds (2005, 2010, 2016/17) of LFS. 
Figure A4: Changes in log earnings (all workers) (two-digit ISCO)
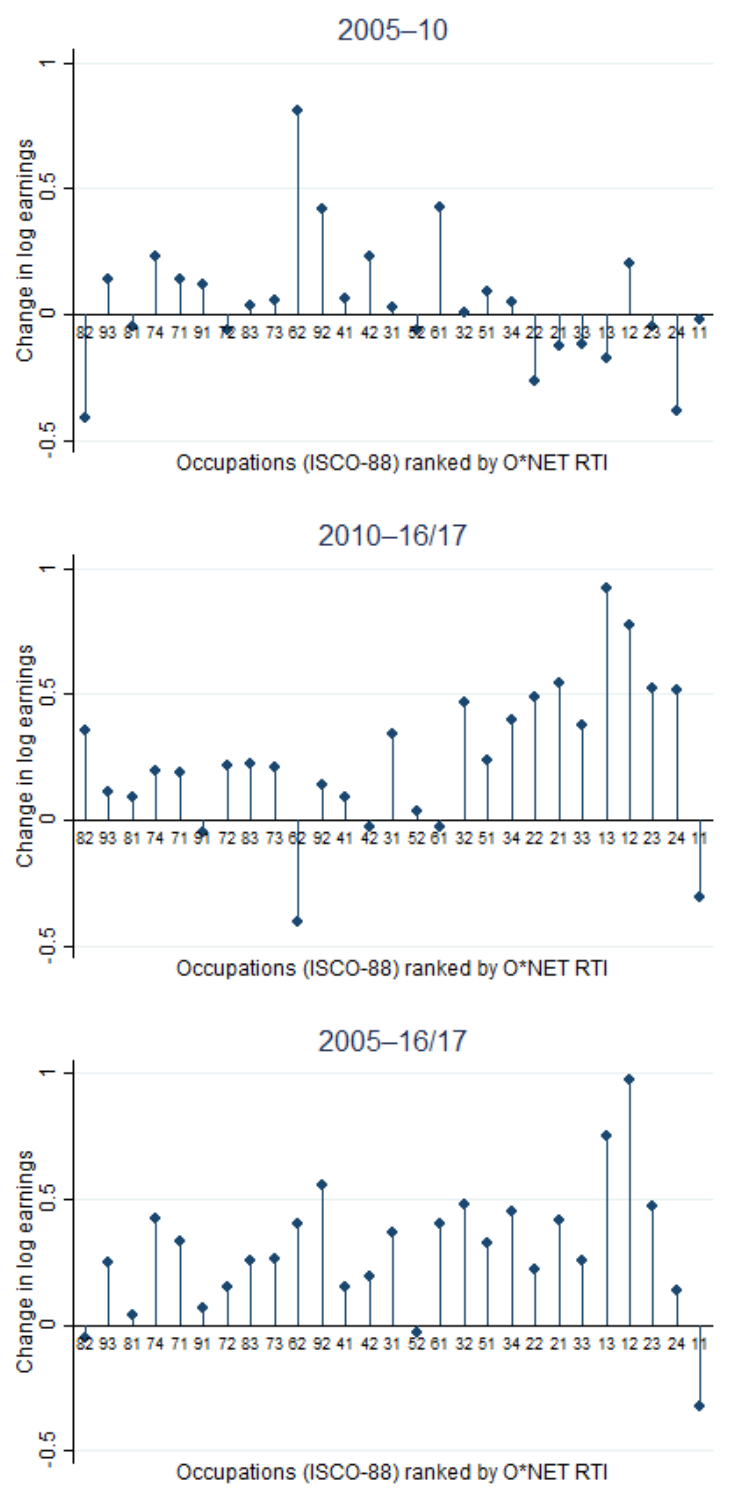

Source: authors' calculation using various rounds $(2005,2010,2016 / 17)$ of LFS. 
Figure A5: Changes in task content measure of different tasks (all workers)

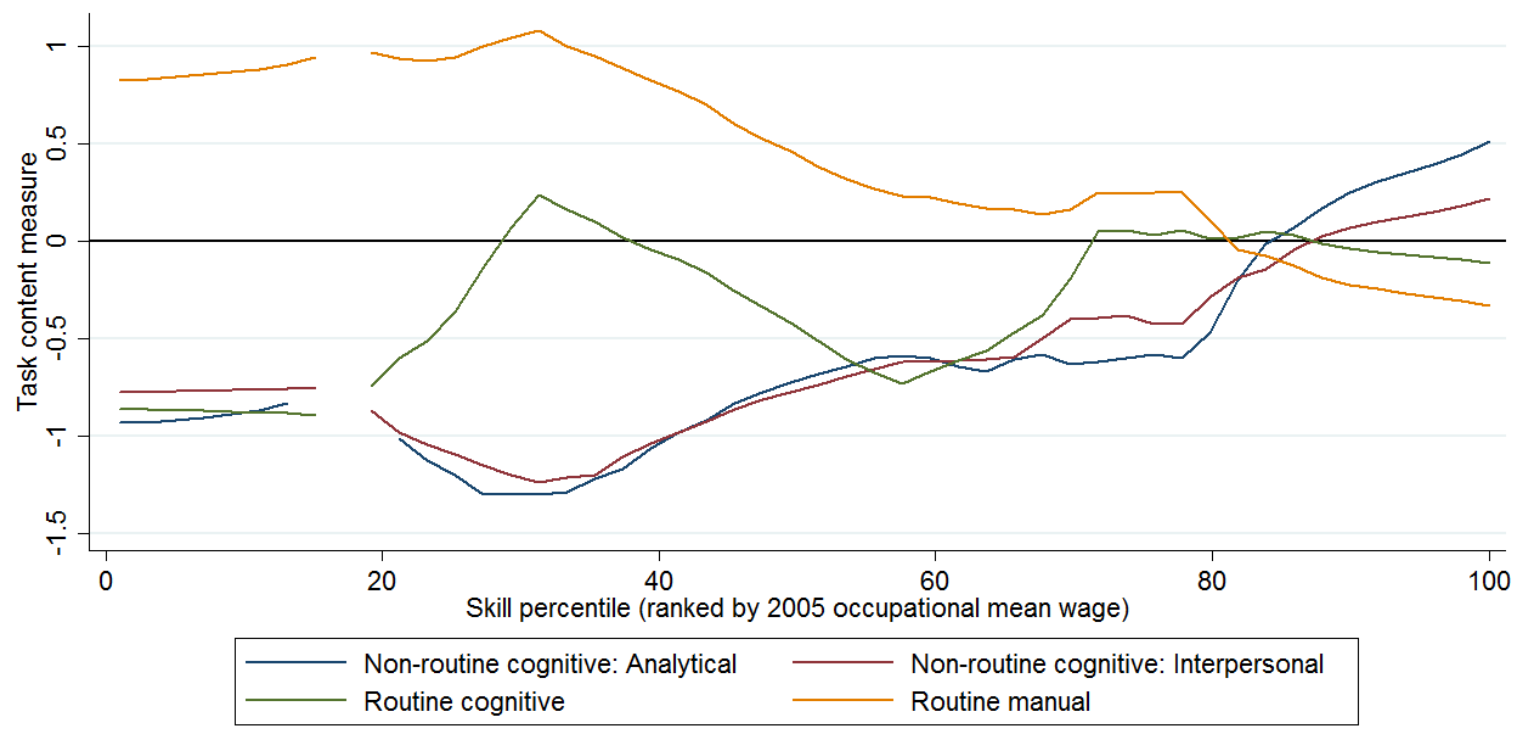

Source: authors' calculation based on various rounds $(2005,2010,2016 / 17)$ of LFS.

Figure A6: Education premium on log earnings (regression 1): (a) male and (b) female
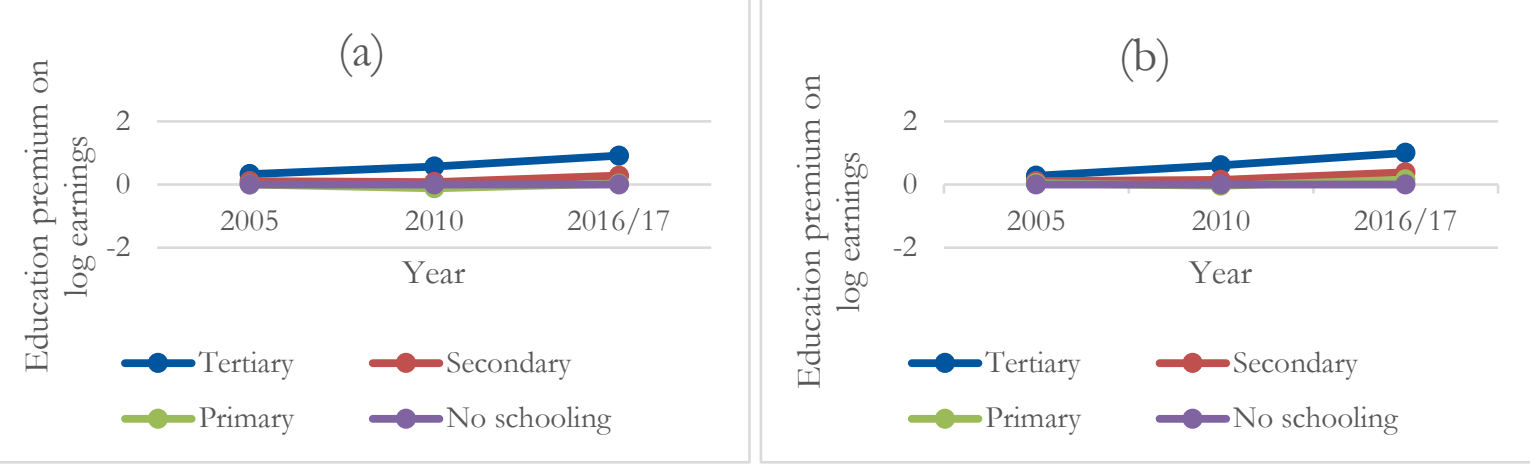

Source: authors' calculation using various rounds $(2005,2010,2016 / 17)$ of LFS.

Figure A7: Education premium on log earnings (regression 2): (a) male and (b) female

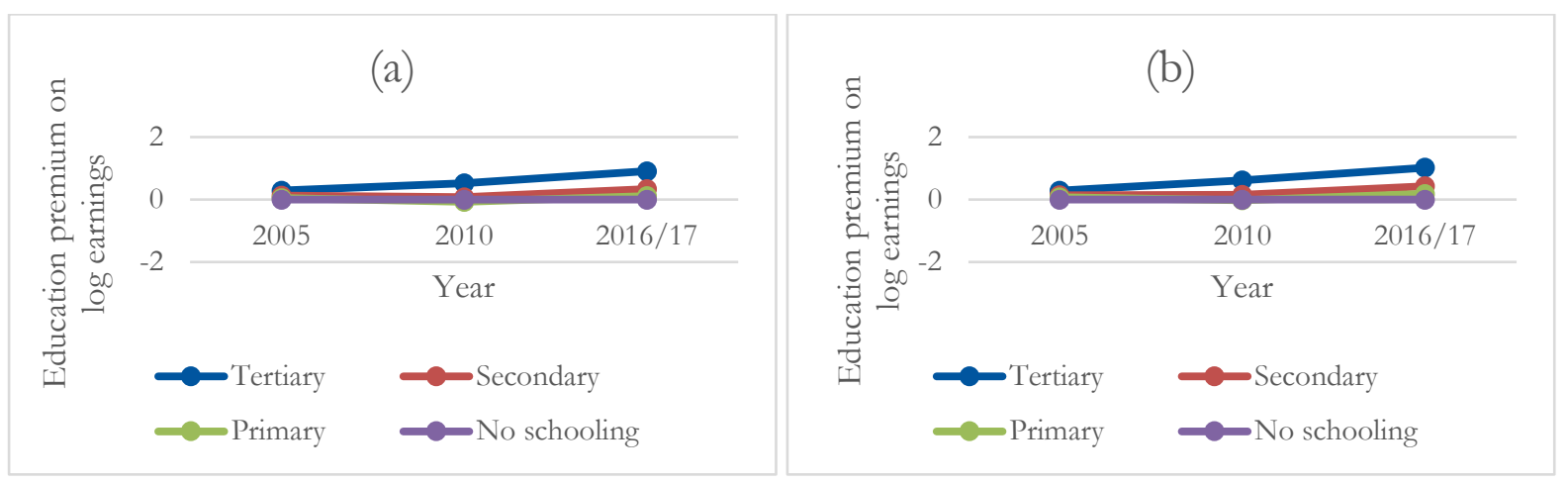

Source: authors' calculation using various rounds $(2005,2010,2016 / 17)$ of LFS. 
Figure A8: Changes in log earnings (two-digit ISCO): (a) all workers; (b) paid workers

(a)

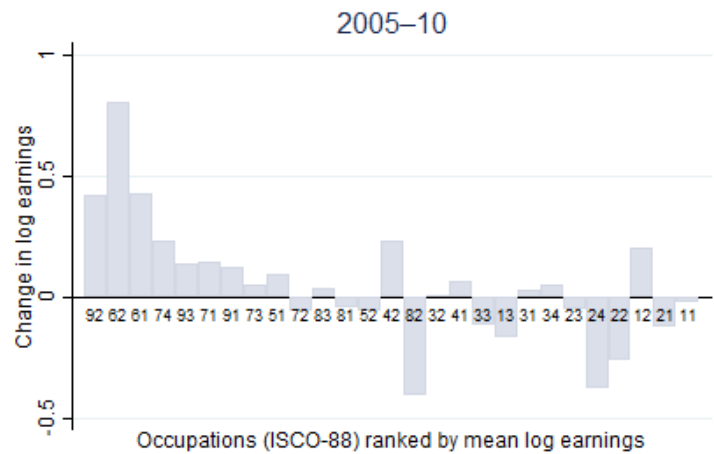

2010-16/17

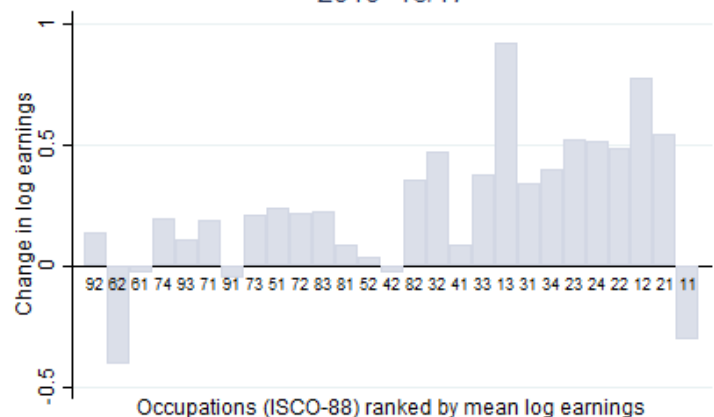

2005-16/17

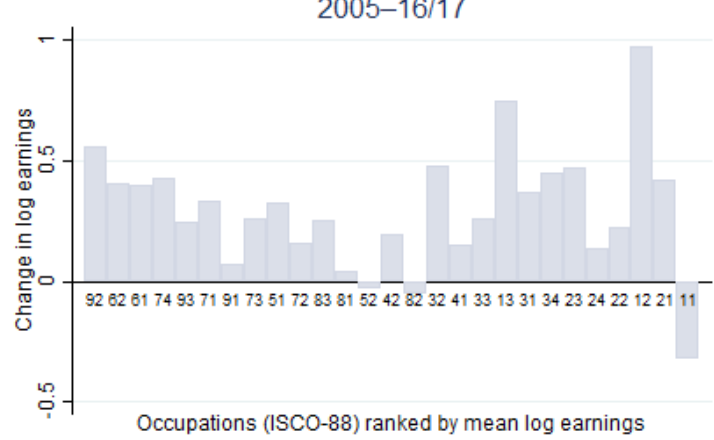

(b)

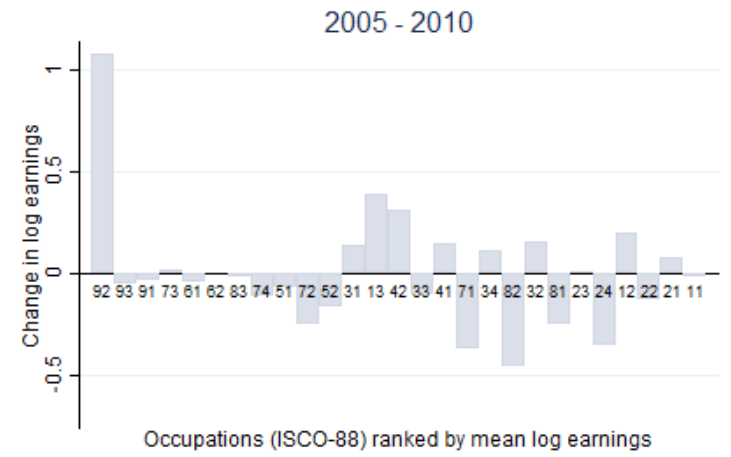

2010 - 2016/17

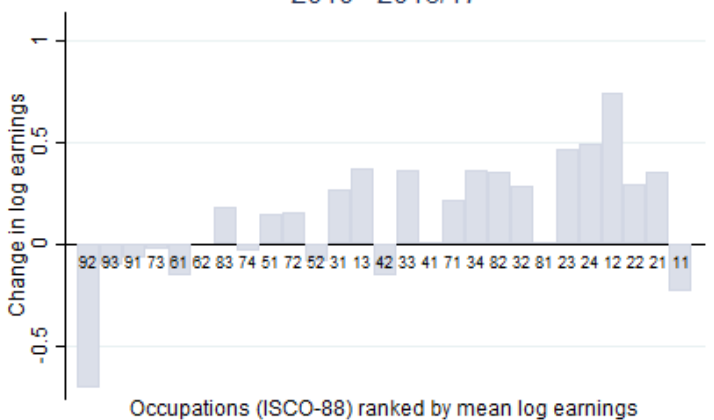

2005 - 2016/17

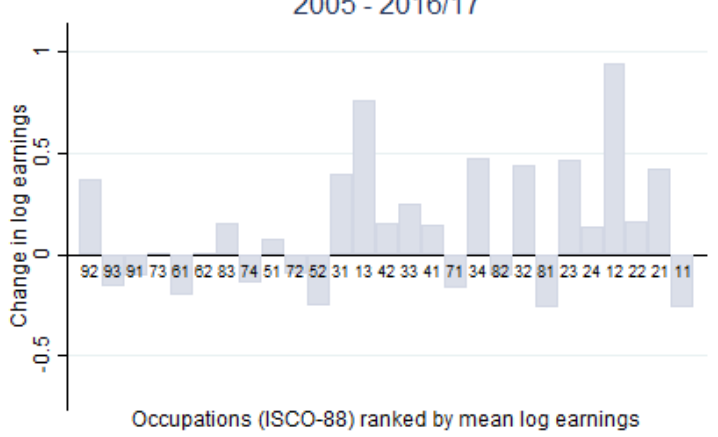

Source: authors' calculation using various rounds (2005, 2010, 2016/17) of LFS. 
Figure A9: Routine-task intensity by earnings percentile, 2005-16/17 (all workers) (two-digit ISCO-88)

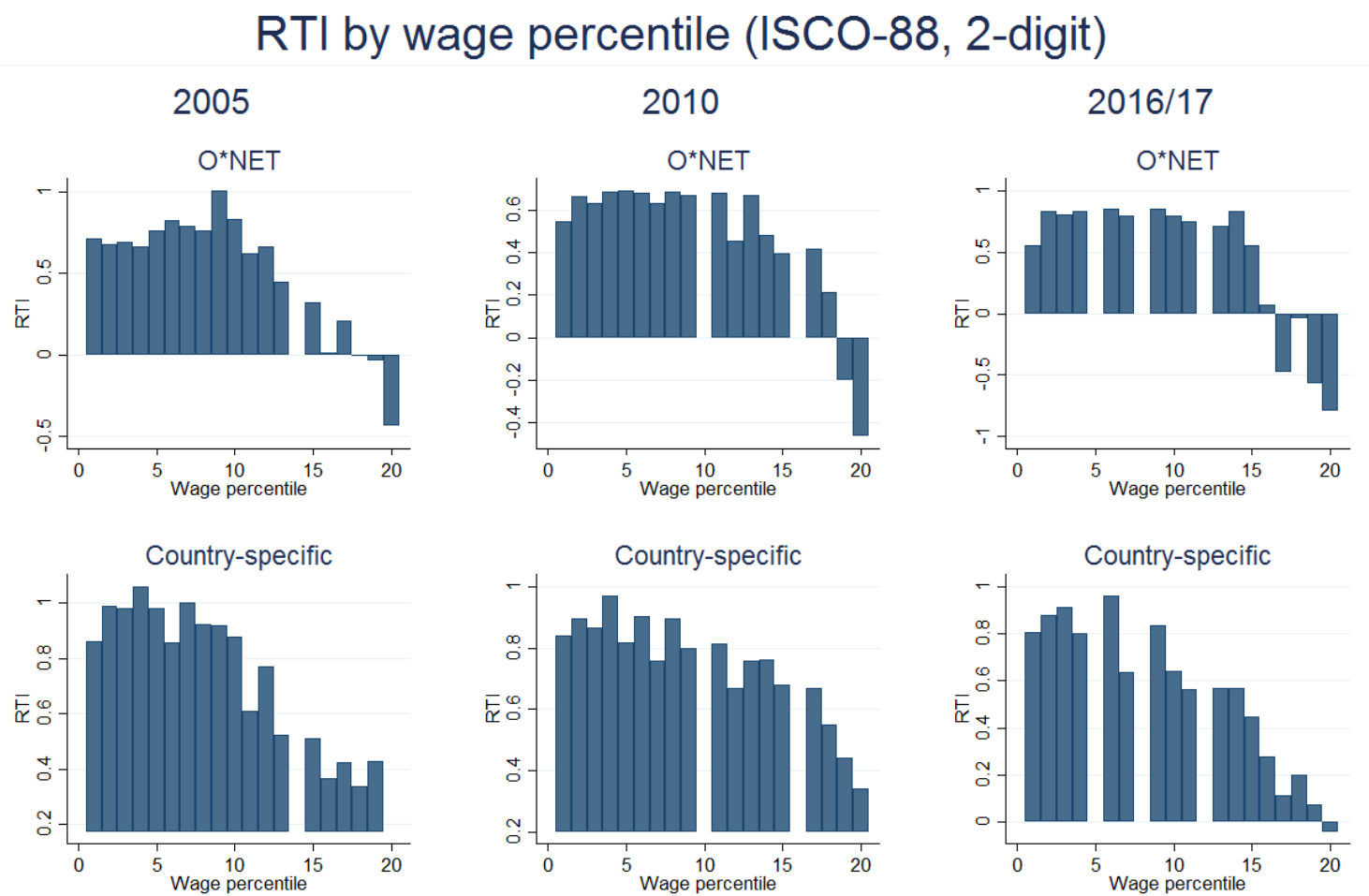

Source: authors' calculation using various rounds (2005, 2010, 2016/17) of LFS.

Figure A10: Decile shares (paid workers)

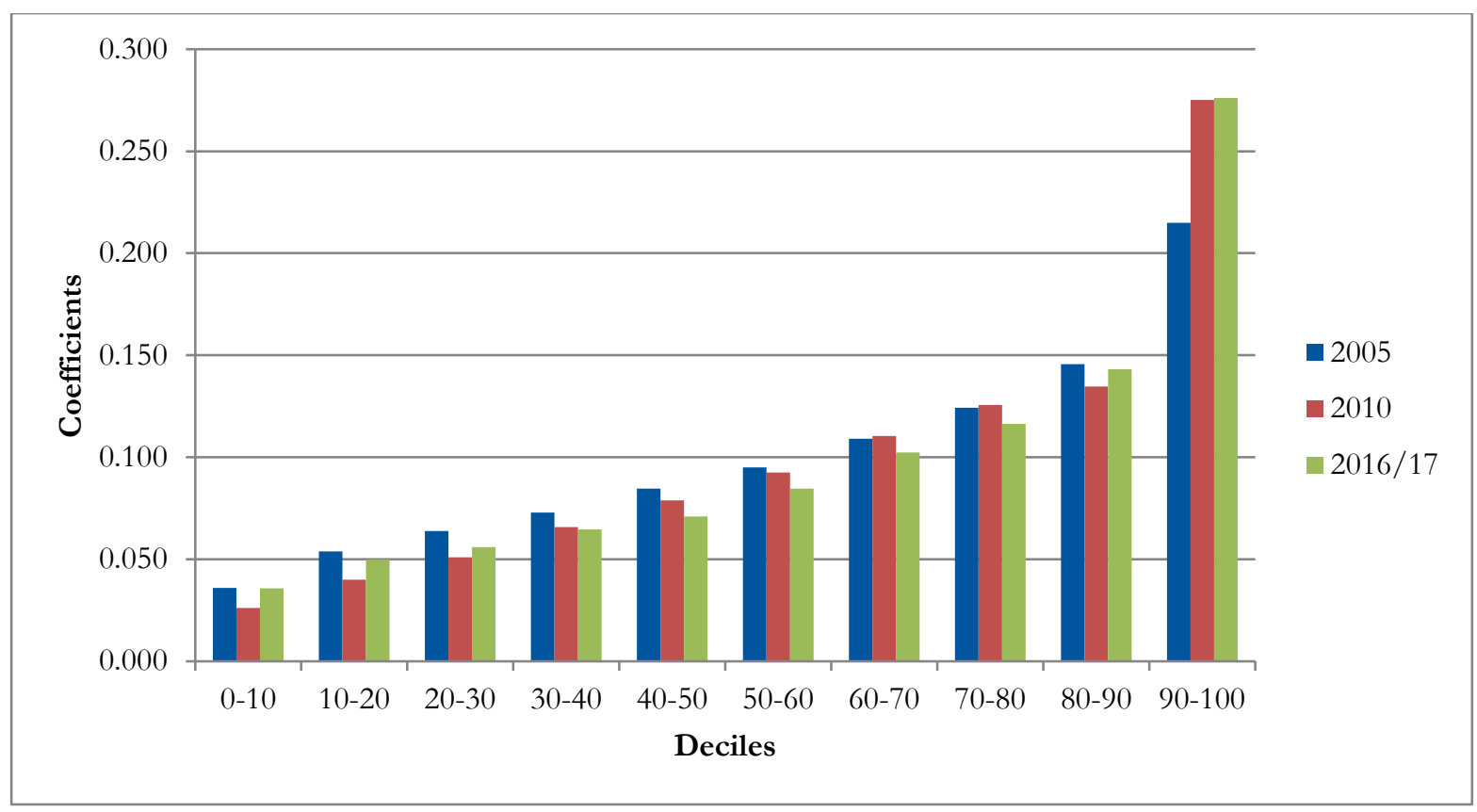

Source: authors' calculation using various rounds (2005, 2010, 2016/17) of LFS. 
Figure A11: Growth incidence curves (all)

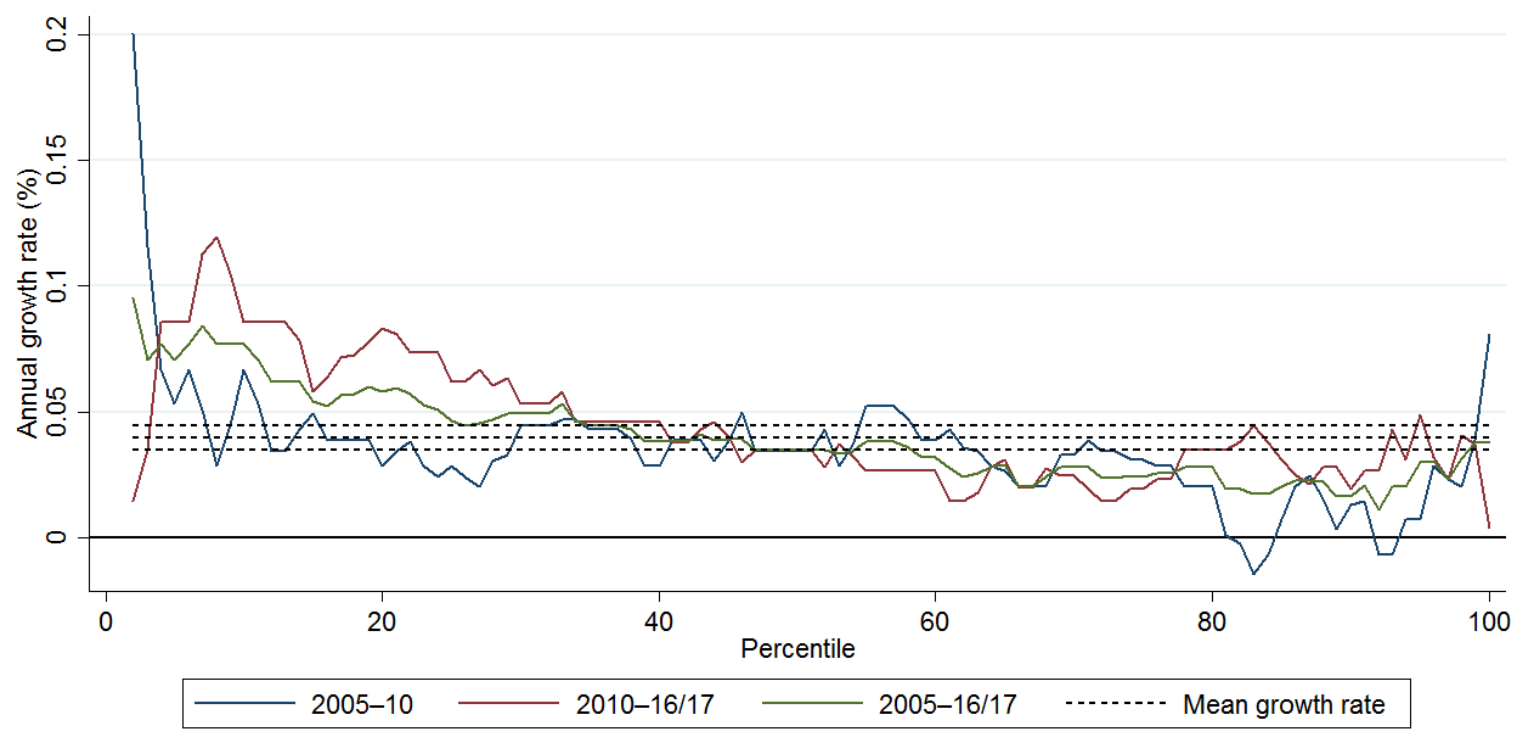

Source: authors' calculation using various rounds $(2005,2010,2016 / 17)$ of LFS.

Figure A12: Lorenz curve (all)

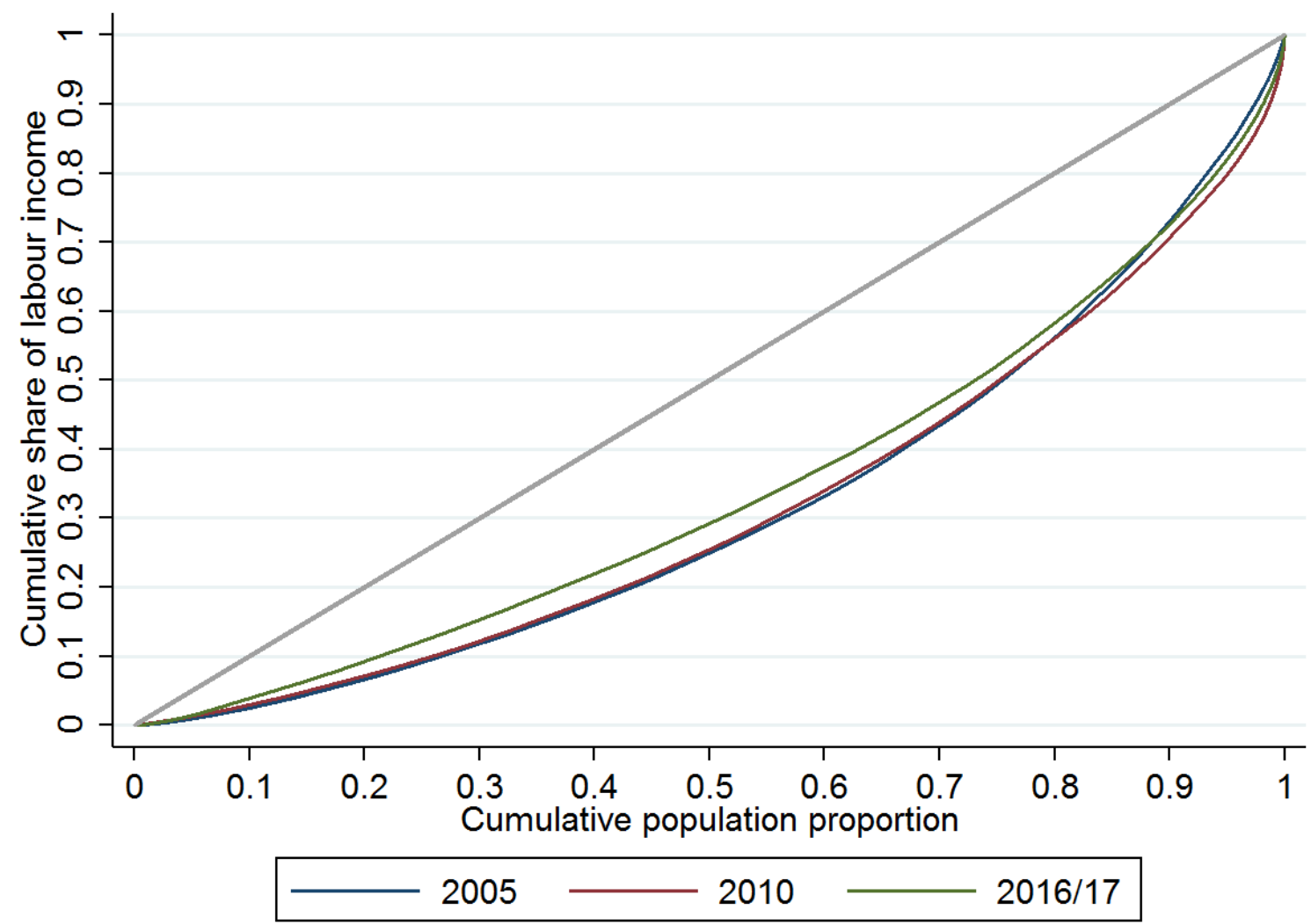

Source: authors' calculation using various rounds (2005, 2010, 2016/17) of LFS. 